\title{
Resolution of Cochlear Inflammation: Novel Target for Preventing or Ameliorating Drug-, Noise- and Age-related Hearing Loss
}

OPEN ACCESS

Edited by:

Peter S. Steyger,

Oregon Health \& Science University,

United States

Reviewed by:

Megan Beers Wood,

St. Jude Children's Research

Hospital, United States

Meiyan Jiang,

Oregon Health \& Science University, United States

*Correspondence:

Federico Kalinec fkalinec@mednet.ucla.edu

Received: 20 May 2017 Accepted: 20 June 2017 Published: 07 July 2017

Citation:

Kalinec GM, Lomberk G, Urrutia RA and Kalinec F (2017) Resolution of Cochlear Inflammation: Novel Target for Preventing or Ameliorating Drug-, Noise- and Age-related Hearing Loss. Front. Cell. Neurosci. 11:192. doi: 10.3389/fncel.2017.00192

\author{
Gilda M. Kalinec ${ }^{1}$, Gwen Lomberk ${ }^{2}$, Raul A. Urrutia ${ }^{2}$ and Federico Kalinec ${ }^{1 *}$ \\ 'Laboratory of Auditory Cell Biology, Department of Head and Neck Surgery, David Geffen School of Medicine, University of \\ California, Los Angeles, Los Angeles, CA, United States, ${ }^{2} E$ pigenetics and Chromatin Dynamics Laboratory, Translational \\ Epigenomic Program, Center for Individualized Medicine (CIM) Mayo Clinic, Rochester, MN, United States
}

A significant number of studies support the idea that inflammatory responses are intimately associated with drug-, noise- and age-related hearing loss (DRHL, NRHL and $\mathrm{ARHL})$. Consequently, several clinical strategies aimed at reducing auditory dysfunction by preventing inflammation are currently under intense scrutiny. Inflammation, however, is a normal adaptive response aimed at restoring tissue functionality and homeostasis after infection, tissue injury and even stress under sterile conditions, and suppressing it could have unintended negative consequences. Therefore, an appropriate approach to prevent or ameliorate $\mathrm{DRHL}, \mathrm{NRHL}$ and $\mathrm{ARHL}$ should involve improving the resolution of the inflammatory process in the cochlea rather than inhibiting this phenomenon. The resolution of inflammation is not a passive response but rather an active, highly controlled and coordinated process. Inflammation by itself produces specialized pro-resolving mediators with critical functions, including essential fatty acid derivatives (lipoxins, resolvins, protectins and maresins), proteins and peptides such as annexin A1 and galectins, purines (adenosine), gaseous mediators ( $\mathrm{NO}, \mathrm{H}_{2} \mathrm{~S}$ and $\mathrm{CO}$ ), as well as neuromodulators like acetylcholine and netrin-1. In this review article, we describe recent advances in the understanding of the resolution phase of inflammation and highlight therapeutic strategies that might be useful in preventing inflammation-induced cochlear damage. In particular, we emphasize beneficial approaches that have been tested in pre-clinical models of inflammatory responses induced by recognized ototoxic drugs such as cisplatin and aminoglycoside antibiotics. Since these studies suggest that improving the resolution process could be useful for the prevention of inflammationassociated diseases in humans, we discuss the potential application of similar strategies to prevent or mitigate $\mathrm{DRHL}, \mathrm{NRHL}$ and $\mathrm{ARHL}$.

Keywords: drug-induced hearing loss, noise-induced hearing loss, age-related hearing loss, inflammation, resolution of inflammation, lipid mediators, annexin A1, galectin

\section{INTRODUCTION}

The most important paradigm recognized and highlighted in this article is that inflammation in any tissue, organ and system, behaves as a beneficial host reaction aimed at protecting individuals from infections and tissue injury. Moreover, inflammation can help to establish an immunological memory that the organism can use later to generate a better 


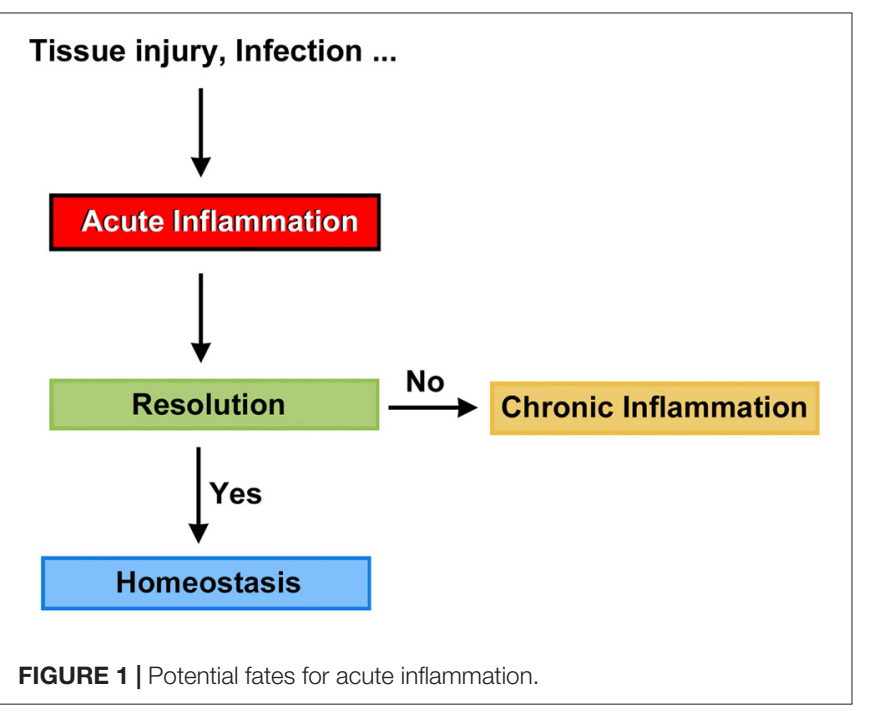

response to a particular infectious agent (Gilroy and De Maeyer, 2015; Headland and Norling, 2015). Therefore, rather than to prevent inflammation, any clinical strategy should be aimed at facilitating its rapid, safe and complete resolution.

Mammals are able to detect the presence of pathogen agents and tissue injury, and initiate complex tissue repair and wound healing programs. At the front line of the host defense mechanism is acute inflammation, a short-term physiologic response aimed to return, at least in part, the organism to the normal phenotype. Not surprisingly, when the timely resolution of inflammation fails, it progresses to chronic inflammation, a condition that can persist for months and even years (Figure 1). Chronic inflammation is linked to the pathogenesis of a number of diseases such as atherosclerosis, type 2 diabetes, rheumatoid arthritis and Alzheimers (Medzhitov, 2008, 2010; Tabas and Glass, 2013), and likely act as a predisposing factor to carcinogenesis (Lee et al., 2013). Thus, the resolution of inflammation may be a crucial target for new therapeutic avenues, and we believe that clinical strategies seeking the timely resolution of inflammatory processes in the cochlea should be considered an important part of the conceptual framework needed to prevent auditory dysfunction.

\section{THE INFLAMMATORY RESPONSE AND ITS RESOLUTION}

\section{General Concepts}

Until recently, the common view on chronic inflammation was that it resulted from exaggerated pro-inflammatory signals during the acute phase, and that its resolution was a passive process mediated by metabolites of the same pro-inflammatory mediators. In other words, that chemo-attractants and other molecules associated with the inflammatory response would eventually dissipate, and the system would automatically reset to its initial stage (Robbins and Cotran, 1979; Tauber and Chernyak, 1991; Serhan, 2011). Studies in the last two decades, however, have led to the formulation of a new paradigm based on the premise that resolution of inflammation results from the engagement and activation of specific genetic, cellular and molecular programs (Perretti, 2015). Thus, it is currently accepted that acute inflammation is terminated by a biosynthetically active process, regulated by endogenous signaling pathways driven by specialized pro-resolving mediators and receptors that: (1) switch from the production of pro-inflammatory mediators to pro-resolution mediators; (2) turn off pro-inflammatory signaling pathways; (3) induce apoptosis of previously recruited inflammatory cells; (4) stimulate the clearance of apoptotic cells by phagocytes; and (5) reinstate, either partially or totally, homeostatic conditions (Alessandri et al., 2013). It has now become evident that the peak of the acute inflammatory response is the beginning of resolution (Serhan and Savill, 2005), with the simultaneous presence of pro-inflammatory and pro-resolution mediators in order to ensure safe cell death and removal, that is, preventing the activation of inflammatory and immune effectors (Gilroy et al., 2004; Hallett et al., 2008; Maderna and Godson, 2009; Perretti and D'Acquisto, 2009; Iqbal et al., 2011; Figure 2). This concept suggests a complex balance between pro-inflammatory and anti-inflammatory events taking place, at least partly, in parallel (Serhan and Savill, 2005; Sugimoto et al., 2016a). Moreover, it strongly corroborates that inflammation is programmed to stay within limits, both spatially and temporally, and to ultimately lead to an active process of completion (Perretti, 2015).

The current mainstay approach for treating inflammationinduced diseases is based on inhibiting the synthesis or activities of the pro-inflammatory mediators. Although there has been success with some of these anti-inflammatory therapies, there are considerable limitations. In particular, the advantages of anti-inflammatory drugs are usually decreased by three factors: redundancy, compensatory pathways and necessity (Tabas and Glass, 2013). For example, many molecules are at work in an inflammatory process, some of them with identical function (redundancy), and targeting one or a few of them may not be enough to obtain significant beneficial results. Likewise, inhibition of one pro-inflammatory pathway may just trigger a compensatory response involving an alternative pathway. Finally, inflammation is a protective reaction (necessity) and, even if the previous two challenges are successfully overcome, the risks associated with inhibiting a natural defense mechanism are often unacceptable (Tabas and Glass, 2013). Thus, there is an increasing awareness that pro-resolution-based strategies may have even more potential than anti-inflammatory therapies for the treatment of multiple diseases (Gilroy et al., 2004; Rossi et al., 2007; Hallett et al., 2008; Serhan et al., 2008; Duffin et al., 2010).

\section{Pro-Resolution Mediators and their Receptors}

In recent years, interest for the resolution phase of inflammatory responses led to the discovery of several specific pro-resolving mediators of diverse nature, including lipids (Serhan et al., 2014), proteins and peptides (Perretti and Dalli, 2009), a purine (Köröskényi et al., 2011; Csóka et al., 2012; Haskó and Cronstein, 2013), gaseous mediators (Wallace et al., 2015), 


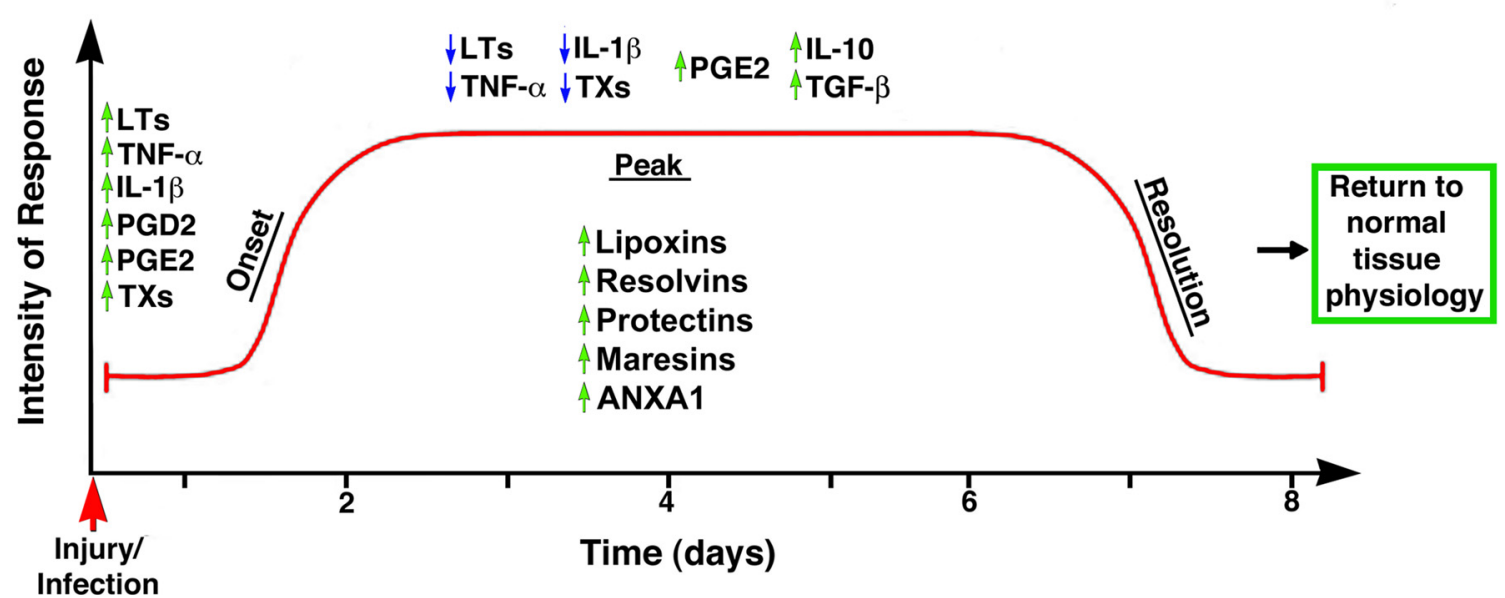

FIGURE 2 | Temporal representation of the biochemical events associated with the onset and resolution of inflammation. The early phase of inflammation is characterized by the up-regulation (green arrows) of pro-inflammatory mediators such as leukotrienes (LTS), tumor necrosis factor- $\alpha$ (TNF- $\alpha$ ), interleukin $1 \beta$ (IL-1 $\beta$ ), prostaglandin D2 (PGD2) and thromboxanes (TXs). Importantly, the anti-inflammatory mediator PGE2 is also up-regulated at this phase, indicating the controlled nature of inflammatory responses. The peak of the inflammatory response coincides with the start of the resolution phase, with down-regulation (blue arrows) of TXs, IL-1 $\beta$, LTs and TNF- $\alpha$, and up-regulation of anti-inflammatory cytokines such as PGE2, IL-10 and TGF- $\beta$; simultaneously, the synthesis and/or release of pro-resolution mediators (e.g., LX, resolvins, protectins, maresins, ANXA1) stop further infiltration of leukocytes and facilitate the removal of apoptotic cells, leading to the successful termination of the inflammatory response and the return to the tissue to its homeostatic condition. Modified from Maderna and Godson (2009).

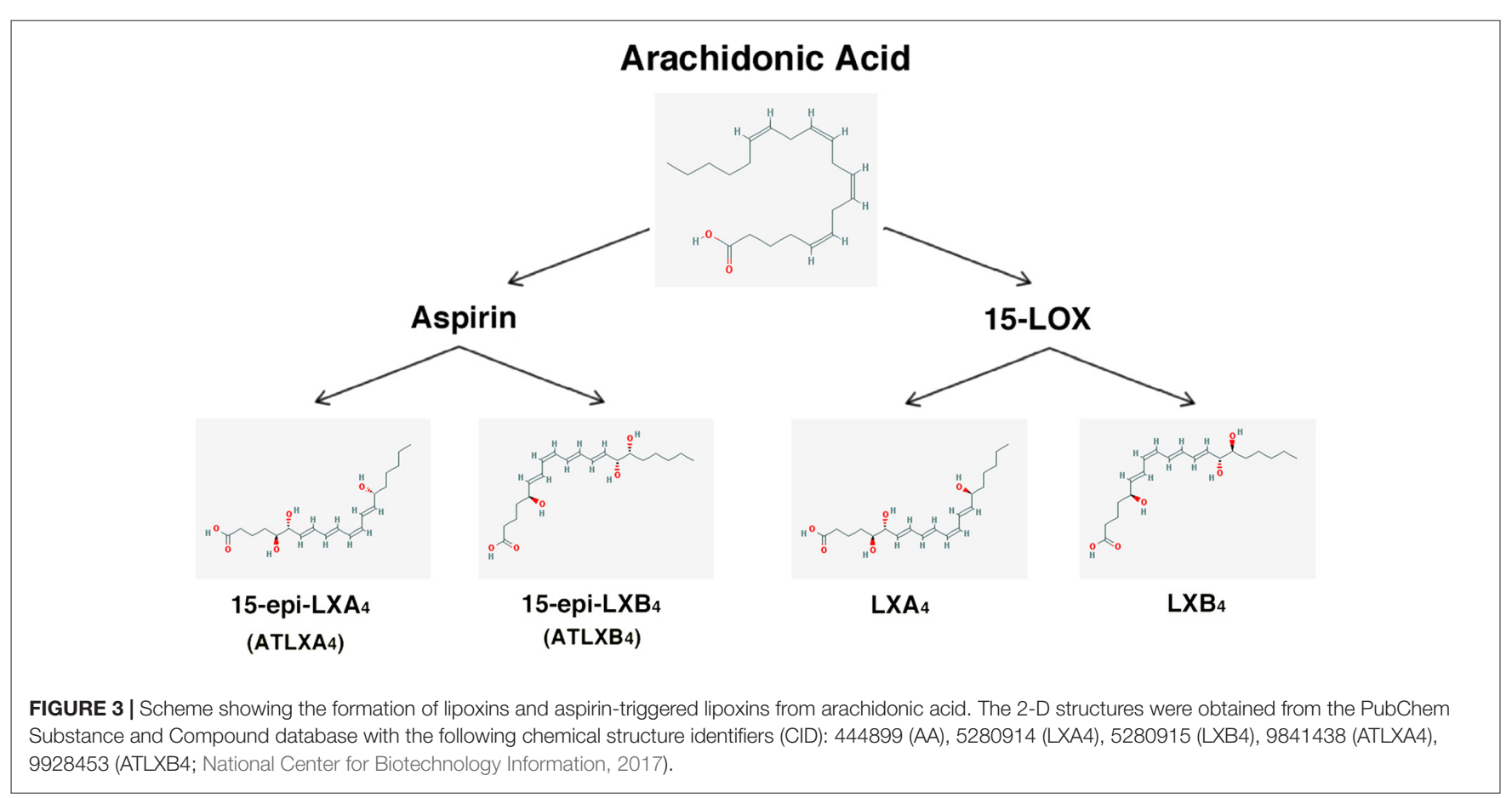

and neuromodulators (Pavlov and Tracey, 2012; Mirakaj et al., 2014). Specialized pro-resolving mediators not only work in inflammatory responses, but they also have important functions in host defense, pain, organ protection and tissue remodeling (Serhan et al., 2015a). More important, synthetic forms of these mediators have potent effects when administered in vivo (Serhan et al., 2014), increasing their clinical value.
To date, the most important pro-resolution mediators described in the literature are:

- Lipoxins (lipoxygenase interaction products; LX), eicosanoids generated in vivo from arachidonic acid (Serhan, 2005; Ryan and Godson, 2010; Figure 3). LX are involved in the inhibition of neutrophil and eosinophil recruitment 


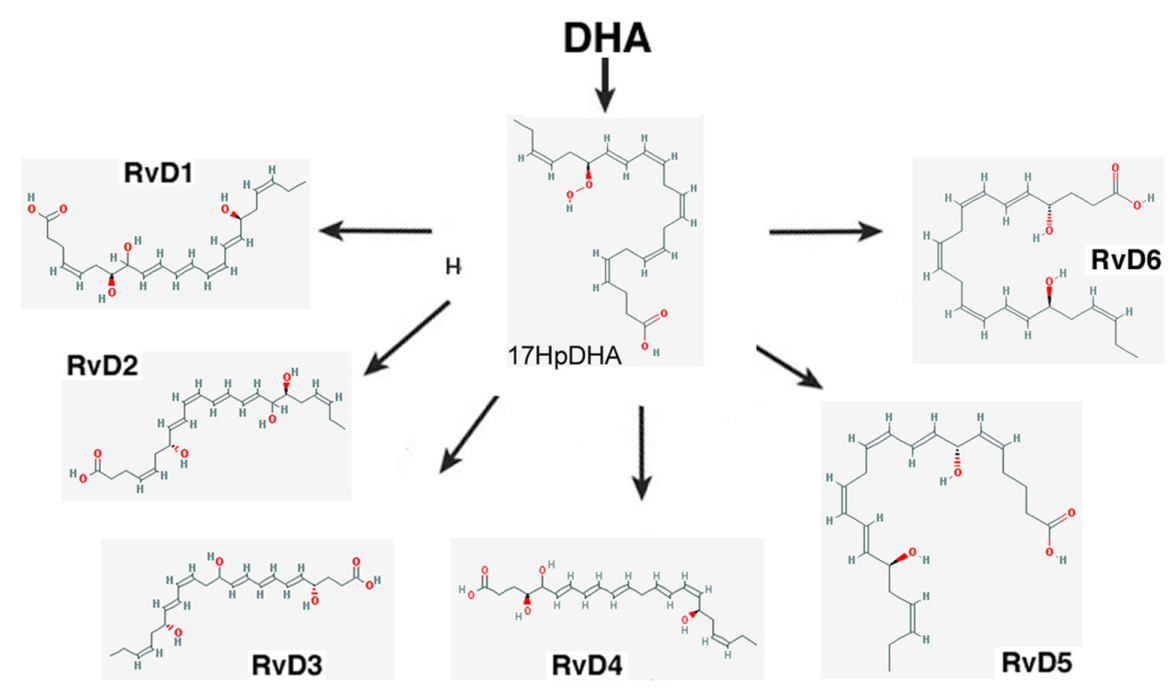

D-series Resolvins

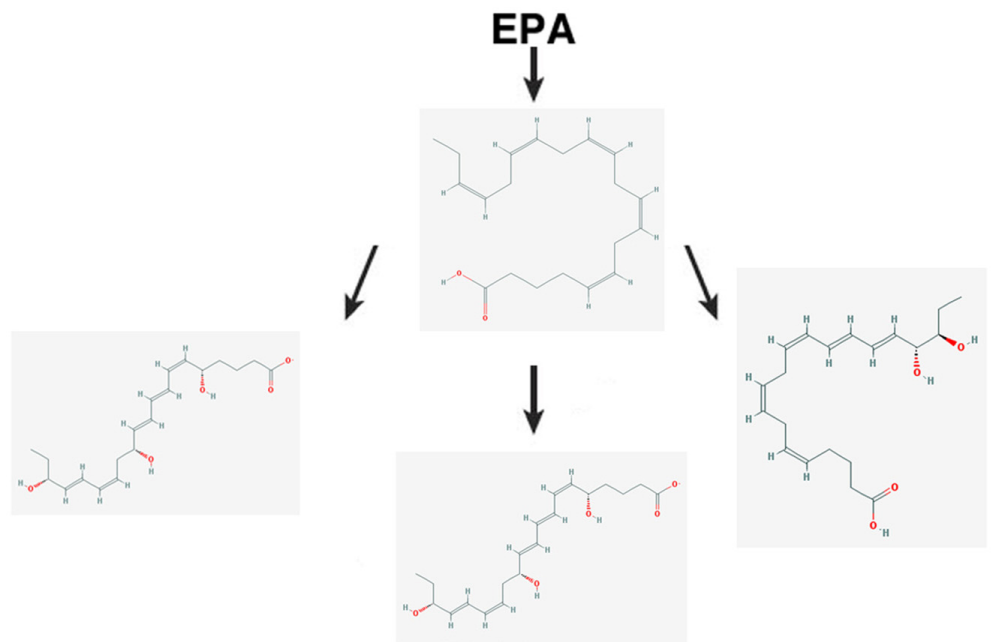

E-series Resolvins

FIGURE 4 | Scheme showing the biosynthesis of D-resolvins and E-resolvins from docosahexaenoic acid (DHA) and eicosapentaenoic acid (EPA), respectively. The 2-D structures were obtained from the PubChem Substance and Compound database with the following CID: 52921992 (17HpDHA), 16061135 (RvD1), 11383310 (RvD2), 53477497 (RvD3), 53477505 (RvD4), 16061139 (RvD5), 25073193 (RvD6), 446284 (18HpETE), 91820117 (RvE1), 16061125 (RvE2), 56848721 (RvE3;

National Center for Biotechnology Information, 2017).

and activation, while enhancing the recruitment of monocytes to sites of injury (Papayianni et al., 1995; Maddox et al., 1997; Wada et al., 2001). In addition, they are able to directly stimulate the expression of anti-inflammatory and pro-resolution genes (Qiu et al., 2001) as well as to regulate NF-kB activation (Decker et al., 2009). Further, they are known to stimulate the clearance of apoptotic cells by macrophages
(Reville et al., 2006). Chronic inflammation has been associated with deficient LX biosynthesis, which makes tissues unable to resolve acute inflammatory reactions (Bandeira-Melo et al., 2000; Pouliot et al., 2000; Bonnans et al., 2002; Karp et al., 2004). Importantly, it has been shown that LX can stimulate the expression of ZO-1, claudin and occludin in cultured epithelial cells (Grumbach et al., 2009), suggesting that they could 

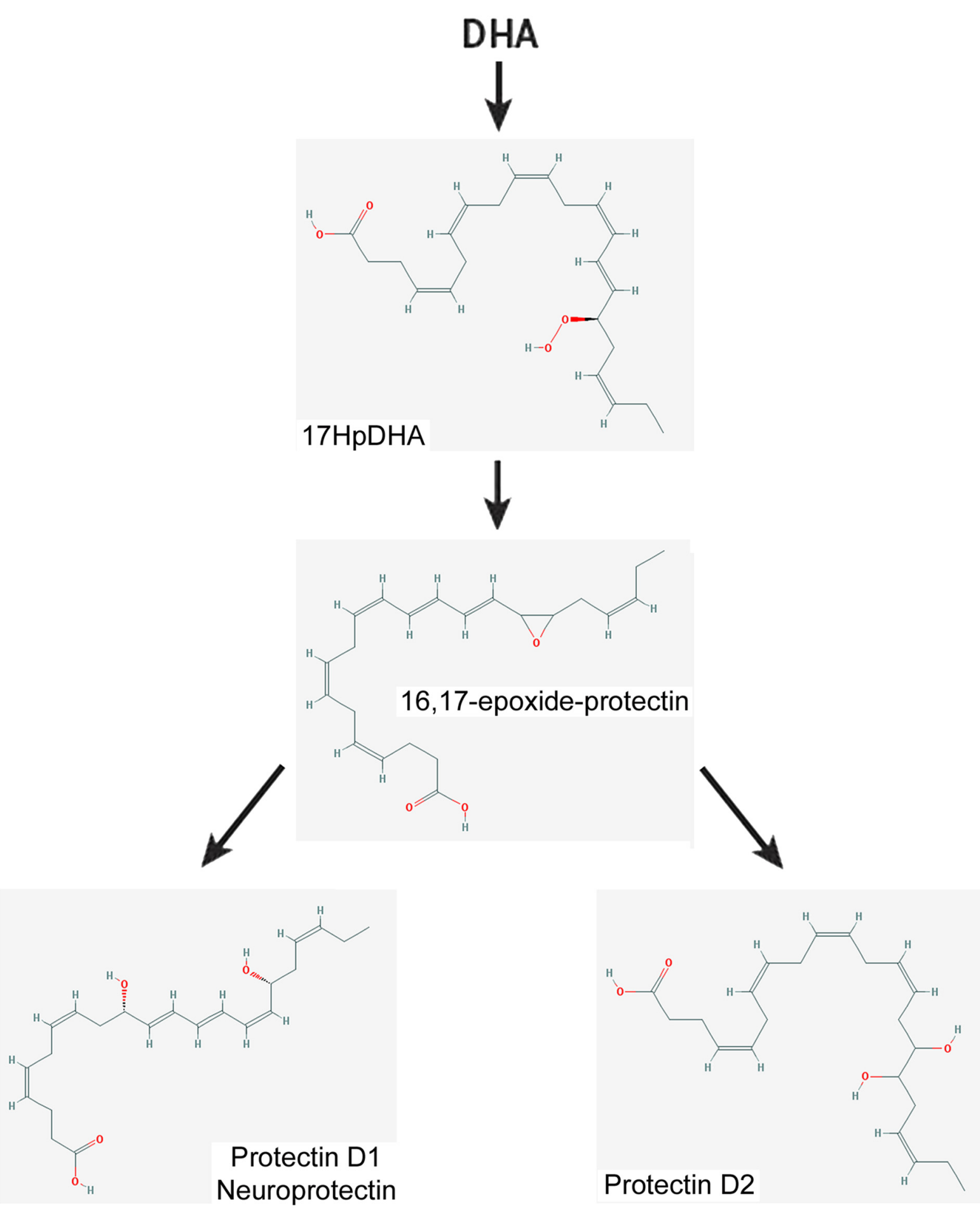

FIGURE 5 | Scheme showing a simplified biosynthetic pathway for protectin 1 and protectin 2 from DHA. The 2-D structures were obtained from the PubChem Substance and Compound database with the following CID: 16061141 (16,17-epoxide-protectin), 16042541 (PRD1), 16061147 (PRD2; National Center for Biotechnology Information, 2017).

have a protective role in the maintenance of the tightjunction barrier at the reticular lamina of the organ of Corti.
Preeminent amongst lipoxins are the positional isomers LXA4 and LXB4 (Pettitt et al., 1991; Rowley et al., 1991; Serhan, 2005; Figure 3). Interestingly, aspirin-mediated 
acetylation of the COX-2 enzyme led to the generation of 15-epi-LX, known as aspirin-triggered LX (ATL; Serhan, 2005). Thus, part the beneficial effects of aspirin in humans may be associated with the endogenous biosynthesis of ATL mimicking the bioaction of native LX. While adequate stimulation induces the near immediate generation of LX and ATL, they are also rapidly inactivated by dehydrogenation and reduction to form triene-containing compounds (e.g., LXA4 into the biologically inactive compounds 15-oxoLXA4, 13,14-dihydro-15-oxo-LXA4 and 13,14-dihydroLXA4) by metabolic enzymes present in leukocytes of the monocyte/macrophage lineage, mainly monocyte/M $\Phi$ (Serhan et al., 1993; Maddox and Serhan, 1996; Clish et al., 2000; Romano, 2006). Although ATL are also converted to their biologically inactive 15-oxo-metabolites, the process is slower, suggesting that they possess an extended activity in vivo (Serhan et al., 1995). As a result of the short lives of the endogenous mediators, stable analogs for both LX and ATL were developed that can resist metabolism, maintaining their structural integrity (Chiang et al., 2005). Studies in animal models suggest that LX analogs could also be useful in humans, providing the rationale for development of innovative anti-inflammatory drugs (Romano, 2005) and "resolution-targeted" therapies (Chiang et al., 2005).

LX are known to bind the G-protein coupled receptor ALX/FRP2 (Chiang et al., 2006). This receptor has been detected on human neutrophils, eosinophils, airway epithelium, monocytes, macrophages, $\mathrm{T}$ cells, synovial fibroblasts and intestinal epithelial cells (Fiore et al., 1994; Maddox et al., 1997; Bonnans et al., 2006; Chiang et al., 2006; Barnig et al., 2013). Importantly, these receptors have also been localized in guinea pig cochlear cells (Kalinec et al., 2009). ALX/FRP2 expression is regulated by inflammatory mediators, transcription factors and epigenetic mechanisms, and LXA4 is known to increase ALX/FRP2 expression by activating its promoter in a positive-feedback fashion (Simiele et al., 2012).

- Resolvins (resolution phase interaction products) are $\omega-3$ essential fatty acids derivatives with powerful multilevel anti-inflammatory and pro-resolving properties (Serhan et al., 1984, 2000a; Pettitt and Rowley, 1991; Arita et al., 2005). They are termed D-series resolvins (RvD) if

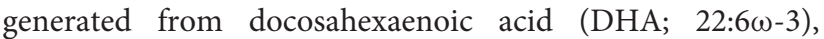
or E-series resolvins ( $\mathrm{RvE}$ ), if the biosynthesis is initiated

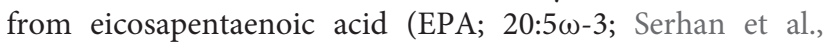
2000a; Serhan and Chiang, 2008; Figure 4). Aspirin is known to oxidize DHA (Kusunoki et al., 1992; Serhan et al., 2004a,b), generating aspirin-triggered D-resolvins (ATR-D; Kusunoki et al., 1992; Serhan et al., 2000b; Serhan and Chiang, 2004). A novel resolvin subfamily, generated

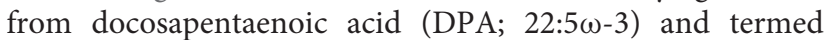
T-series (RvT), has also been recently described (Dalli et al., 2015a).

Resolvins have a key role in the resolution of inflammatory responses, regulating the migration of neutrophils and resolution macrophages to sites of inflammation as well as reducing the levels of pro-inflammatory mediators (Serhan et al., 2015a). RvDs and RvEs also promote phagocytosis of apoptotic neutrophils (Schwab et al., 2007; Krishnamoorthy et al., 2010), reduce activation and aggregation of platelets (Dona et al., 2008), and regulate the function of $\mathrm{T}$ and B cells (Ariel et al., 2006; Ramon et al., 2012). The just discovered RvTs, on the other hand, could be crucial in the resolution of inflammation triggered by bacterial infection (Dalli et al., 2015a). In mice, the local application of RvD1 significantly decreases the number of apoptotic cells and macrophages in diabetic wounds, accelerating wound closure and granulation tissue formation (Spite et al., 2014). In animal models of sterile inflammation, RvE1 decreases the expression of the genes encoding TNF- $\alpha$, IL- $1 \beta$ and VEGF (Jin et al., 2009) as well as IL-12 production (Poorani et al., 2016). RvEs and RvDs are more active than their precursors EPA and DHA, and they are known to induce significant effects even at nanomolar concentrations. They have potent in vivo actions in many important human pathologies, such as obesity and diseases affecting the vascular (Miyahara et al., 2013), airway (Levy and Serhan, 2014), and ocular systems, as well as in reactions involving pain, fibrosis and wound healing (Serhan and Chiang, 2013; Spite et al., 2014).

RvD1 and its aspirin-triggered epimer RvD1 (ATR-D1) bind the ALX/FRP2 receptor, just like LX (Fiore et al., 1994; Chiang et al., 2006; Krishnamoorthy et al., 2012). Interestingly, RvD1 and ATR-D1, as well as RvD3, and RvD5, have also been shown to bind and signal through a specific receptor termed RvD1-R (Sun et al., 2007; Krishnamoorthy et al., 2010, 2012; Chiang et al., 2012; Dalli et al., 2013b). It appears that RvD1 differentially interacts with RvD1-R during periods of homeostasis and with ALX/FRP2 during the resolution phase of inflammation (Krishnamoorthy et al., 2012). In turn, RvD2 and RvE have specific receptors termed, respectively, RvD2-R (Chiang et al., 2015) and RvE-R (Arita et al., 2005; Campbell et al., 2007; Parolini et al., 2007; Cash et al., 2008; Du and Leung, 2009; Barnig et al., 2013).

- Protectins also derive from DHA (Hong et al., 2003; Serhan et al., 2006; Figure 5). Protectins, like resolvins, control the magnitude and duration of inflammation in animal models (Schwab et al., 2007; Serhan and Petasis, 2011), fight bacterial and viral infections (Chiang et al., 2012), and can increase animal survival (Serhan and Chiang, 2013).

Two members of the family have been described, protectin-D1 and protectin-D2 (Dalli et al., 2013a). PD1, originally identified in neural tissues (murine brain cells and human microglial cells), is also known as neuroprotectin (Kohli and Levy, 2009). The identity of the protectin receptor/s is not yet known, although it has been proposed that, in humans, they bind to high affinity sites in the plasma membrane of neutrophils (Marcheselli et al., 2010). Interestingly protectins have been shown to regulate the expression of the Peroxisome Proliferator-Activated Receptor- 


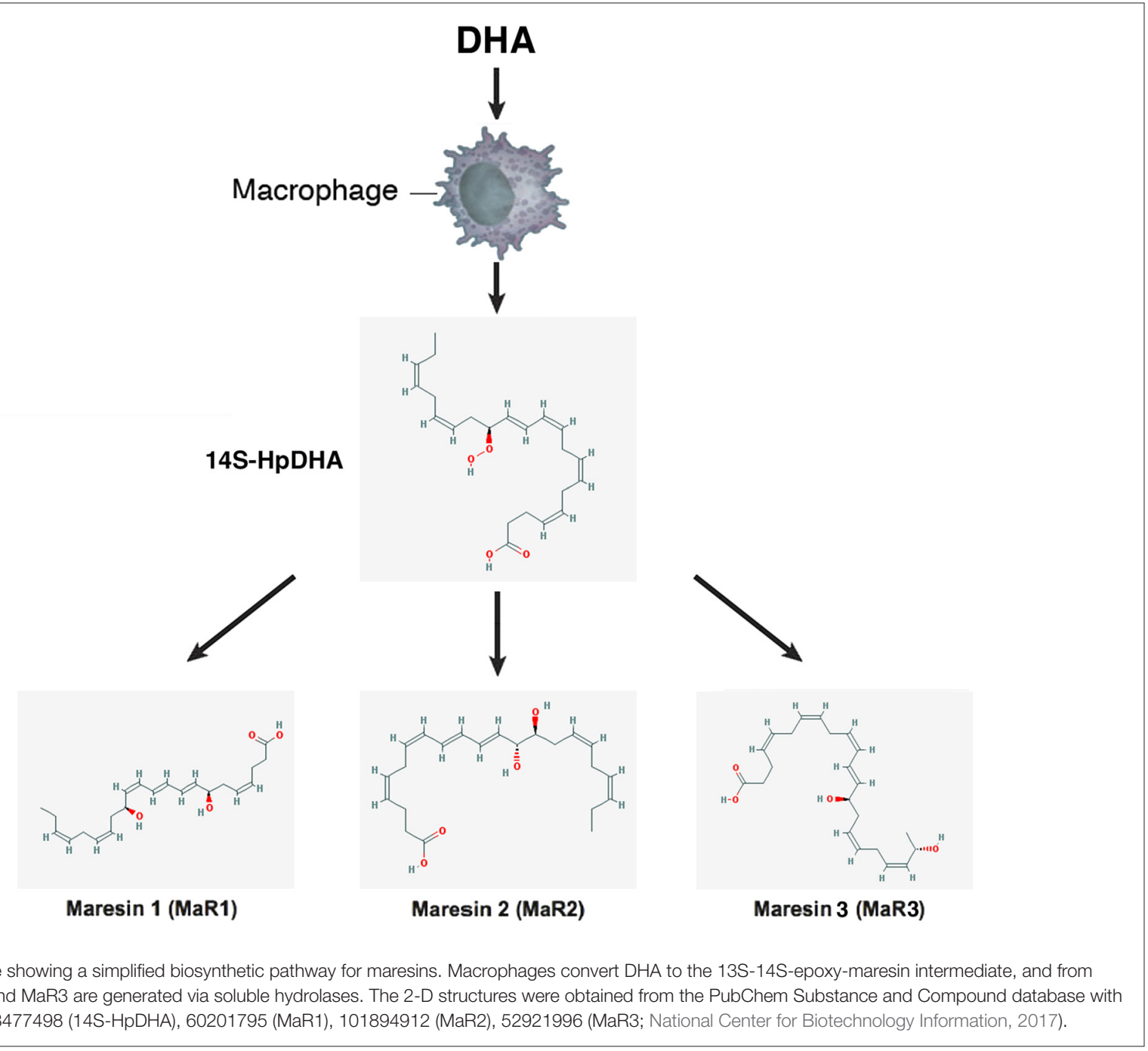

$\gamma$ (PPAR- $\gamma$; White et al., 2015), a member of a nuclear hormone receptor superfamily that, acting as transcription factors, regulate inflammation, immune responses and metabolic processes that influence lipid metabolism, glucose homeostasis, cell differentiation, obesity and cancer (Chinetti et al., 2003; Moraes et al., 2006).

- Maresins (macrophage mediators in resolving inflammation) are anti-inflammatory and pro-resolving lipid mediators generated by macrophages from DHA (Serhan et al., 2009; Figure 6). To date, three members of the family have been described, MaR1, MaR2 and MaR3 (Dalli et al., 2013a), which display potent anti-inflammatory and pro-resolving actions even at the nanogram range (Poorani et al., 2016). Maresins are known to stimulate phagocytosis of polymorphonuclear (PMN) by macrophages (Serhan et al., 2015b), increase the number of regulatory $\mathrm{T}$ cells and decrease the production of interleukins 5 and 13 (IL-5, IL-13; Krishnamoorthy et al., 2015), as well as inhibit the production of leukotriene B4 (LTB4; Serhan et al., 2015b), contributing to the completion of the resolution phase of inflammatory responses.
The identity of the receptor/s through which maresins signal is still unknown.

NOTE: Several sulfido-conjugates of maresins, protectins and D-resolvins are also biologically active (Dalli et al., 2014, 2015b). These sulfido-conjugates are usually produced from DHA by activated phagocytes, and they are very effective in stimulating inflammatory resolution and tissue regeneration (Duvall and Levy, 2016).

- Annexin A1 (ANXA1) is a powerful anti-inflammatory and pro-resolving protein. ANXA1 synthesis and release is regulated by glucocorticoids (Sugimoto et al., 2016b), and it is considered a pivotal homeostatic mediator (Perretti and Dalli, 2009), and an important modulator of both the innate and adaptive immune systems (D'Acquisto et al., 2008; Perretti and D’Acquisto, 2009). Experimental evidence suggests that ANXA1, in addition to decreasing pro-inflammatory cytokines while increasing the production of immunosuppressive and pro-resolving molecules, is able to induce macrophage reprogramming toward a 


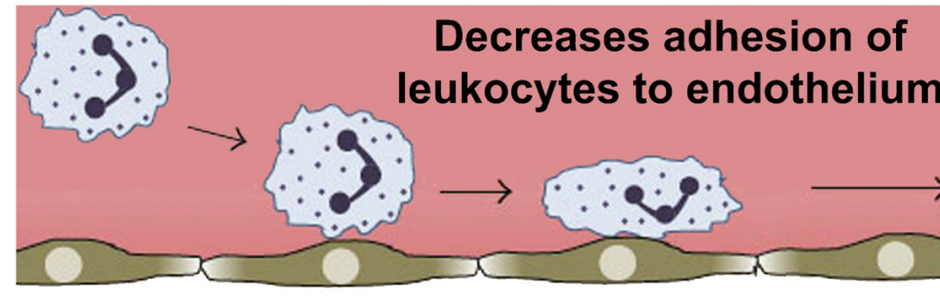

\section{Inhibits migration of leukocytes}

$$
\leftarrow
$$

$\leftarrow$

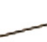

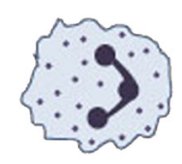

$<$

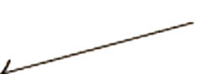

\section{Inhibits diapedesis}

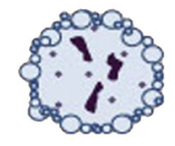<smiles>C1CC1</smiles>

Promotes reprogramming of macrophages

\section{Induces apoptosis and phagocytosis of leukocytes}

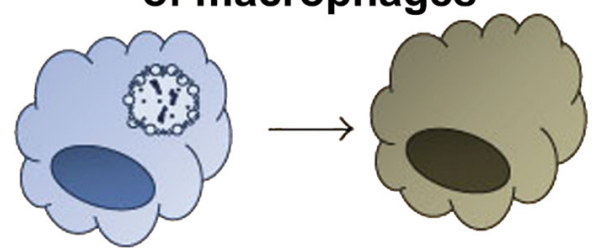

FIGURE 7 | Anti-inflammatory and pro-resolving effects of annexin A1 (ANXA1). Pharmacological administration of ANXA1 or its mimetic N-terminal peptides results in decreased migration and adhesion of leukocytes to the endothelium and inhibition of their passage through the walls of the blood vessels (diapedesis). In addition, ANXA1 is able to induce apoptosis, and clearance of apoptotic leukocytes by macrophages. Furthermore, ANXA1 promotes the reprogramming of macrophages toward a pro-resolving phenotype, and even the generation of non-professional phagocytic cells. Modified from Sugimoto et al. (2016b).

resolving phenotype, and even converting somatic cells into non-professional macrophages (Sugimoto et al., 2016a; Figure 7). Several studies indicate that the anti-inflammatory and pro-resolution activity of ANXA1 is associated with its $\mathrm{N}$-terminus. Importantly, short synthetic peptides from this domain retain the receptor binding specificity of the full protein and have most of their effects, but they are more resistant to inactivation (Perretti and D'Acquisto, 2009).

Since many of the cellular and molecular processes associated with the anti-inflammatory properties of glucocorticoids are, actually, modulated by ANXA1, pharmacologic interventions based on ANXA1 could be equally effective as steroids without their negative side effects. The association of ANXA1 with lipid droplets in auditory Hensen cells from guinea pigs, as well as its potential role in the resolution of cochlear inflammation, have been discussed in a recent review (Urrutia and Kalinec, 2015).

ANXA1, as well as short synthetic peptides from its N-terminal domain, specifically bind to ALX/FPR2, the same receptor that binds LXA4 and resolvins D1/E1(Perretti and D'Acquisto, 2009). Thus, the ALX/FPR2 receptor is shared by a variety of peptide/protein and lipid ligands, mediating many functions of relevance for inflammation (Anong et al., 2009). The promiscuity of ALX/FPR2 seems to be linked to a network of both pro-inflammatory and pro-resolving signaling pathways (Le et al., 2007; Brancaleone et al., 2011). It was demonstrated that distinct ALX/FPR2 domains are required for signaling by different agonists; for instance, while ANXA1-mediated signaling involves the N-terminal region and extracellular loop II of ALX/FPR2, LXA4 activates
ALX/FPR2 by interacting with the extracellular loop III and its associated transmembrane domain (Bena et al., 2012).

- Galectins, a family of glycan-binding proteins, are currently considered key players in several programs that control maturation, activation, differentiation, polarization, trafficking, cytokine synthesis and viability of immune cell populations (Rabinovich and Toscano, 2009; MendezHuergo et al., 2014; Rabinovich and Conejo-García, 2016). By crosslinking specific glycoconjugates, different members of the galectin family (15 members identified to date) behave as either pro-inflammatory or anti-inflammatory agents, regulating the initiation, amplification and resolution of acute and chronic inflammatory responses (Rabinovich et al., 2002; Rubinstein et al., 2004). Several studies identified Gal-1, Gal-3 and Gal-9 as direct players in the modulation of acute and chronic inflammatory diseases, autoimmunity and cancer, and are increasingly used as targets for drug discovery (Norling et al., 2009). Gal-1 has been associated with a range of anti-inflammatory effects on various cells types (Rabinovich et al., 2000; Dias-Baruffi et al., 2003; La et al., 2003). Gal-3, in turn, is widely pro-inflammatory, and it appears to be involved in the transition to chronic inflammation (Henderson and Sethi, 2009). Gal-3 is known to enhance the phagocytic capabilities of neutrophils, a fact that may in part account for its protective role in infections (Farnworth et al., 2008). Finally, the ability of Gal-9 to induce T-cell apoptosis makes it a potent anti-inflammatory protein (Tsuchiyama et al., 2000; Zhu et al., 2005; Katoh et al., 2007), with several pro-resolution properties including the increase of leukocyte apoptosis and phagocytic clearance (Iqbal et al., 2011). 
After being secreted galectins bind to glycoprotein targets, forming galectin-glycan complexes that regulate the organization of glycosylated receptors as well as their internalization and signaling (Rabinovich and Croci, 2012; Thiemann and Baum, 2016). Thus, they are able to stimulate different signaling cascades associated with inflammation (Norling et al., 2009; Rabinovich and Toscano, 2009; Blidner et al., 2015) and regulate the activity of immune cells by controlling the function of relevant glycosylated receptors.

- Adenosine is a ubiquitous metabolite of ATP generated as a result of cellular injury or stress, and is released from cells via specific transporters or during apoptosis or necrosis (Haskó and Cronstein, 2013). Adenosine is an important immunosuppressive and tissue-healing factor, and its production and extracellular concentrations are significantly increased in inflammation (see Aherne et al., 2011 and references therein). In the auditory system adenosine has been associated with protective mechanisms against noiseand drug-related hearing loss (for a review, see Vlajkovic et al., 2009). In mice, adenosine release is known to be induced by aspirin (Cronstein et al., 1999), and it is possible that adenosine could be the real effector of some of the pro-resolution properties of aspirin.

Adenosine interacts with purinergic receptors type 1 (P1) on the plasma membrane of inflammatory and immune cells (Bours et al., 2006), regulating their function and limiting inflammatory tissue destruction (Haskó and Cronstein, 2004). Adenosine-activated P1 receptors are further divided into A1, A2 and A3 subtypes, with $A 1$ and $A 3$ inhibiting and A2 stimulating adenyl cyclase after being activated by adenosine; in addition, the A2 subtype is subdivided into A2A (high-affinity) and A2B (low-affinity) adenosine receptors (Ralevic and Burnstock, 1998). Since the particular effects of adenosine depend on which receptor is activated, the physiological effects of adenosine will depend on the relative expression of their receptors in a particular cell, tissue, or organ (Ralevic and Burnstock, 1998). In mammalian cochleae, adenosine receptors $\mathrm{A} 1$ and $\mathrm{A} 2 \mathrm{~A}$ are abundantly expressed in inner hair cells (IHCs), Deiters cells and spiral ganglion neurons, whereas A3 is localized in IHCs and outer hair cells (OHCs), as well as in Deiters, pillar, Hensen, Claudius, spiral ganglion, inner and outer sulcus cells (Vlajkovic et al., 2009).

- $\mathrm{NO}, \mathrm{H}_{2} \mathrm{~S}$ and $\mathrm{CO}$, nitric oxide, hydrogen sulfide and carbon monoxide, respectively, are gaseous substances that can act as signaling molecules (Wallace et al., 2015). NO has the ability to regulate apoptosis of inflammatory cells, with lower concentrations of NO usually being cytoprotective, while supra-physiological concentrations trigger cell death (Kim et al., 1999; Brüne, 2005). These pro- and anti-apoptotic properties are cell-specific, and depend largely on the NO isoforms involved (Taylor et al., 2003). In inflammatory cells, low concentrations of endothelial and neuronal isoforms of NO synthase (eNOS and nNOS) have a protective effect, whereas higher concentrations from the inducible isoform (iNOS) are more likely to induce apoptosis (Nicotera et al., 1997). Since the resolution of inflammatory processes requires death and clearance of inflammatory cells, NO-mediated regulation of apoptosis may be critical for ensuring the return to homeostasis.

$\mathrm{H}_{2} \mathrm{~S}$ exerts potent inhibitory effects on a wide range of leukocyte functions (Zanardo et al., 2006; Pálinkás et al., 2015). Importantly, $\mathrm{H}_{2} \mathrm{~S}$ is an avid scavenger of other cytotoxic substances, including peroxynitrite (Whiteman et al., 2004), superoxide anion (Muzaffar et al., 2008), hypochlorous acid (Whiteman et al., 2005) and hydrogen peroxide (Whiteman et al., 2010), all of them important for oxidative stress. In addition, ANXA1 mediates some of the anti-inflammatory actions of $\mathrm{H}_{2} \mathrm{~S}$ (Brancaleone et al., 2014), and there is strong evidence that $\mathrm{H}_{2} \mathrm{~S}$ helps to restore tissue function by up-regulating enzymes that drive tissue repair and preserve mitochondrial function (Goubern et al., 2007; Lagoutte et al., 2010; Mimoun et al., 2012).

$\mathrm{CO}$ is produced via the inducible isoform of the enzyme heme oxygenase (HO-1), which is a sensor of cellular stress, and it has been shown that the $\mathrm{CO}$ it generates may limit tissue injury (Motterlini and Foresti, 2014). Like $\mathrm{NO}$ and $\mathrm{H}_{2} \mathrm{~S}, \mathrm{CO}$ has anti-apoptotic, anti-inflammatory and anti-proliferative effects, and these functions seem to be associated, at least in part, with their influence on oxidative stress, redox signaling and cellular respiration (Motterlini and Foresti, 2014). In the clinic, in addition to the oral administration of CO-releasing molecules ("CO-RMs" or "CORMs"), it is relatively common to use CO as an inhaled gas (Wallace et al., 2015). It has been reported that inhaled $\mathrm{CO}$ reduces neutrophil infiltration and stimulates the activity of HO-1 and phagocytosis by resolution macrophages (Chiang et al., 2013). Importantly, inhaled $\mathrm{CO}$ also increases the production of RvD1 and Mar1 while decreasing LTB4 (Chiang et al., 2013).

The gaseous mediators $\mathrm{NO}, \mathrm{H}_{2} \mathrm{~S}$ and $\mathrm{CO}$, in contrast to other signaling molecules, do not have specific receptors. Their effects result from direct interaction with a great number of different proteins and genes (Wallace et al., 2015).

- Neuromodulators, like acetylcholine and netrin-1, control immune function and anti-inflammatory responses via a vagus nerve-mediated reflex (Pavlov and Tracey, 2012). Acetylcholine receptors, including $\alpha 7 \mathrm{nAChR}$, act as molecular targets for the vagus-mediated signals, and several $\alpha 7 \mathrm{nAChR}$ agonists have shown anti-inflammatory properties in human volunteers (Kitagawa et al., 2003). The local expression of netrin-1, an axonal guidance molecule known to stimulate the production of resolvins, is also regulated by the vagus nerve (Ly et al., 2005; Mirakaj et al., 2010, 2011; Aherne et al., 2012). In addition to promoting the generation of resolvins, Netrin-1 activates resolution by decreasing the recruitment of PMN cells in vitro and in vivo while increasing the recruitment of monocytes and its uptake of apoptotic PMNs (Mirakaj et al., 2014). Interestingly, netrin-1 was localized in the early postnatal rat and mouse cochlea, and it has been suggested that it could have an important role in promoting the growth of spiral ganglion cells' neurites as well as guiding their axons (Gillespie et al., 2005; Lee and Warchol, 2008). Moreover, it has been shown that insulin-like growth factor 1 (IGF-1) up-regulates the expression of netrin-1 in the neonatal mouse inner ear (Hayashi et al., 2014), and recent results suggest 
that netrin-1 could be a key mediator of the protective role of IGF-1 against the ototoxic effects of aminoglycosides (Yamahara et al., 2017).

- Aspirin as a pro-resolution mediator

Aspirin is a potent inhibitor of cyclo-oxygenases (COX) and lipoxygenases (LOX), interfering with the synthesis of pro-inflammatory mediators (Forge and Schacht, 2000; Gilroy, 2005b). However, unlike many other anti-inflammatory agents considered resolution-toxic because they delay complete resolution (Gilroy et al., 1999; Schwab et al., 2007), aspirin promotes resolution mechanisms (Gilroy and Perretti, 2005; Serhan, 2007). At high doses $(\sim 1 \mathrm{~g})$, aspirin is antiinflammatory, but it is pro-resolution at lower doses $(\sim 81 \mathrm{mg})$ because of the synthesis of the pro-resolution mediator ATLA4 and up-regulation of its receptor ALX/FRP2. Since ATLA4 inhibits the pro-thrombotic eicosanoid thromboxane, a low dose aspirin is commonly used for the prevention of vascular diseases (Morris et al., 2009).

In addition to these effects, and as already mentioned, aspirin-acetylated COX-2 is the origin of ATL and ATR (Serhan, 2005). Thus, it is argued that the most important mechanism of action of aspirin is the induction of pro-resolution mediators (Gilroy and Perretti, 2005; Gilroy, 2005a,b). Importantly, aspirin may acetylate COX-2 in one cell type and ATL and ATR be generated in a different one in a process known as transcellular metabolism (Serhan et al., 2000a; Gilroy et al., 2004; Gonzalez-Períz and Claria, 2007). For example, 15-hydroxyeicosatetraenoic acid (15-HETE), generated by aspirin acetylation of COX-2 in endothelial cells, may be released and then metabolized to ATL by inflammatory cells. These relatively unrecognized pathways and compounds may represent new ways to develop novel "resolution-targeted" therapeutics (Chiang et al., 2005).

There is no receptor for aspirin, but it is known to stimulate a variety of receptor-mediated signaling pathways, for example, by the production of ATL and ATR (Gilroy, 2005b). The main receptor for ATL and ATR-D1 is ALX/FRP2, the same molecule that binds LX, ANXA1 and RvD1/E1 (Fiore et al., 1994; Chiang et al., 2006; Krishnamoorthy et al., 2012). Moreover, ATR-D1 also activates RvD1-R, the specific receptor known to bind RvD1, RvD3 and RvD5 (Sun et al., 2007; Krishnamoorthy et al., 2010, 2012; Chiang et al., 2012; Dalli et al., 2013b). Thus, indirectly through the activation of the signaling pathways mediated by these receptors (as well as others mechanisms such as the release of adenosine), aspirin has a unique ability to induce a variety of pro-resolution effects.

There is considerable interest in elucidating whether aspirin also favors resolution in humans (Morris et al., 2009, 2010). It is already known that, in humans, low-dose aspirin triggers ATL production just like in animal models (Chiang et al., 2004). Thus, the combination of aspirin with $\omega-3$ essential fatty acids might have a beneficial impact on diseases associated with inflammation in many organs, including the cochlea. Moreover, it has been suggested that aspirin could slow down the progression of age-related hearing loss (ARHL; Lowthian et al., 2016).

\section{Resolution of Inflammation in the Mammalian Cochlea-General Concepts}

For many years, the cochlea was considered an "immuneprivileged" organ because of the presence of a tight junctionbased blood-labyrinth barrier (BLB; Harris, 1983, 1984; McCabe, 1989). A number of more recent studies, however, showed that resident macrophages are always present in the cochlear lateral wall as well as in the spiral limbus and the scala tympani (ST) side of the basilar membrane (Frye et al., 2017), and they are activated by various types of insults, including noise exposure, ischemia, mitochondrial damage and surgical stress (Hirose et al., 2005; Zhang W. et al., 2012; Fujioka et al., 2014; Figure 8). Moreover, experimental data suggests that BLB permeability is regulated by inflammatory cytokines released by macrophages in the spiral ligament and macrophage-like melanocytes in the stria vascularis (Zhang W. et al., 2012; Fujioka et al., 2014), and that inflammation would increase BLB permeability to some ototoxic drugs (Koo et al., 2015).

The association of inflammation with ototoxicity was originally based on evidence that glucocorticoids protected against sensorineural hearing loss (Kanzaki and Ouchi, 1981). Later studies demonstrated that the cochlea can mount inflammatory responses not only in response to pathogens but also to toxic insults mediated by drugs, noise or immune challenges (sterile inflammation; Rock et al., 2010). For example, several ototoxic drugs are known to induce cell apoptosis and inflammation in the cochlea both directly or through the generation of reactive oxygen species (ROS; Kaur et al., 2011; Oh et al., 2011). Noise trauma also induces an inflammatory response in the inner ear (Fujioka et al., 2006), and studies in mice suggest that chronic environmental noise exposure could induce cochlear damage and hearing loss via inflammatory processes (Tan et al., 2016). Moreover, it has been suggested that low-grade inflammation may be also linked to some of the auditory problems usually associated with aging (Lowthian et al., 2016), otitis media, meningitis and autoimmune inner ear disease (Gloddek et al., 1999; Trinidad et al., 2005; CayeThomasen et al., 2009). Furthermore, cochlear inflammation is a common result of cochlear surgery and the insertion of cochlear implants (Backhouse et al., 2008; Okano et al., 2008).

Akin to pathogen-induced inflammation, the resolution phase in sterile inflammation is also initiated by apoptosis and clearance of damaged cells (Medzhitov, 2008). The similar response is due to the fact that pathogens and the byproducts of cellular damage, known as damage-associated molecular patterns (DAMPs), stimulate the same pattern recognition receptors (PRRs; Kono and Rock, 2008; Zitvogel et al., 2010). Early inflammation caused by DAMP-PRR signaling is considered an evolutionarily preserved mechanism for controlling the spread of pathogens or necrotic tissue (Wood and Zuo, 2017). Interestingly, until recently the accepted paradigm was that apoptosis, the physiological form of cell death, occurred without DAMPs; necrosis, in contrast, was thought to lead to the generation of DAMPs, followed by activation of inflammatory and 


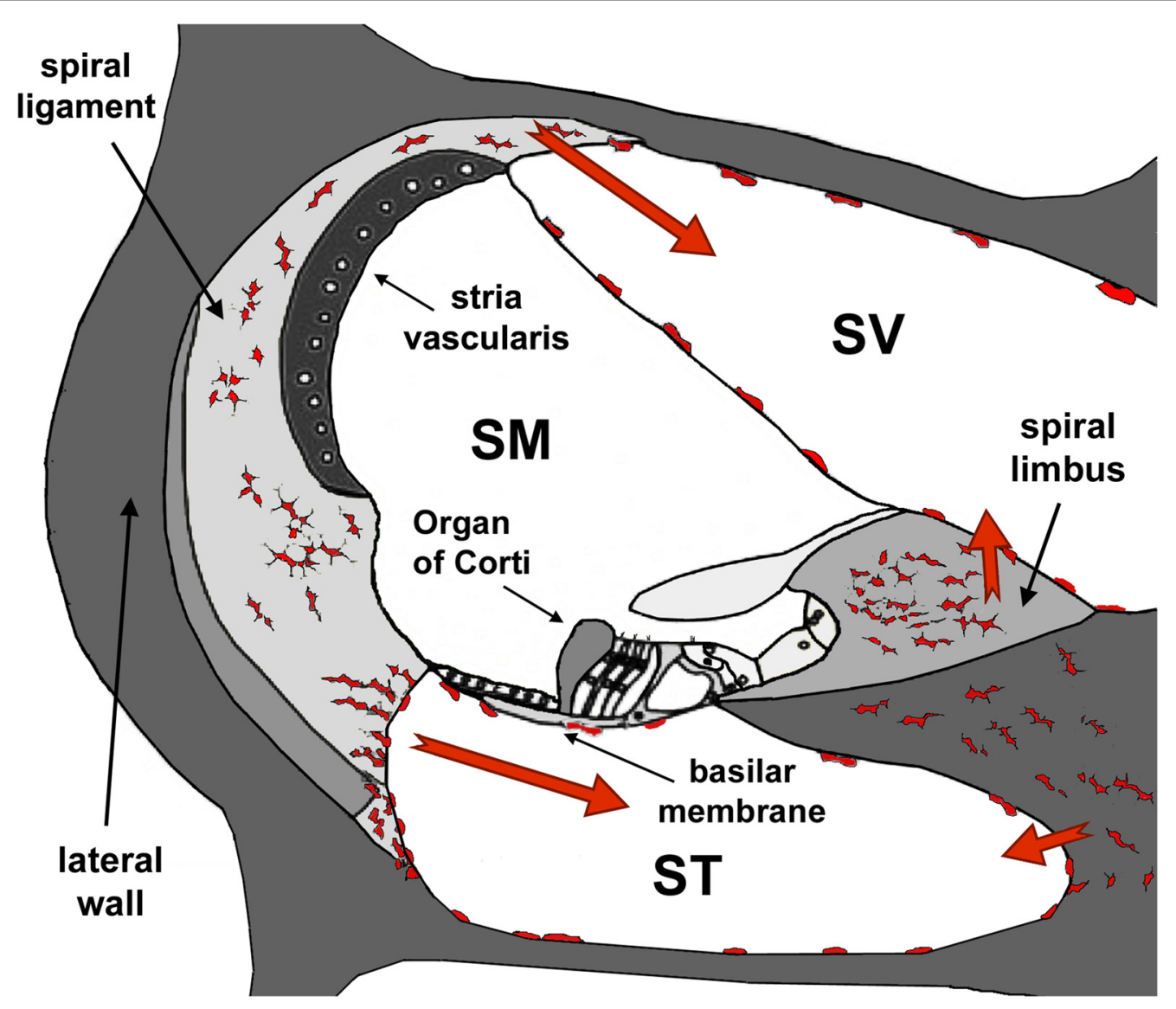

FIGURE 8 | Diagram of a section of the cochlea. Note the three cochlear ducts, the scala vestibule (SV), the scala media (SM) and the scala tympani (ST). The auditory organ, the organ of Corti, sits at the SM. At the onset of inflammation, leukocytes and resident macrophages in the lateral wall and the spiral limbus migrate to the SV and the ST but, except in cases of extreme cochlear damage, they do not penetrate into the SM. Modified from Urrutia and Kalinec (2015).

immune pathways (Kono and Rock, 2008). However, the idea that accidental necrosis would always elicit inflammation and immune responses, and that apoptosis would be antiinflammatory, is a misconception. In some cases apoptotic cells trigger immune responses (Green et al., 2009), whereas cell necrosis can be executed in a regulated and safe manner (Garg et al., 2010).

Thus, in the cochlea, PRR activation rapidly leads to the activation of resident macrophages, the release of pro-inflammatory cytokines, and ROS production, causing apoptosis of damaged cells and infiltration of immune cells into the scala vestibule (SV) and the ST. The nature of the immune cells infiltrating the cochlea has been discussed in a recent review (Wood and Zuo, 2017), and will not be addressed here. The infiltrating cells transform into activated macrophages and express pro-inflammatory proteins (Yang et al., 2015). Whereas leukocytes are essential elements of the immune system, providing the first line of defense against invading pathogens, they require appropriate regulation to avoid tissue damage (Hallett et al., 2008; Headland and Norling, 2015). This is particularly important in the cochlea, where migrant leukocytes may disrupt the tight junction barrier at the reticular lamina in the organ of Corti. Without tightjunctions, the endolymph of the scala media (SM) would mix with the perilymph of the ST, eliminating the differences in electrical potential between these two chambers, shutting off the cochlear amplification mechanism and inducing apoptosis of outer hair cells (Kalinec et al., 2009). Consistent with this idea, leukocytes and macrophages are never found in the SM except in cases of extreme, irreversible cochlear damage (Hirose and Liberman, 2003; Hirose et al., 2005; Tornabene et al., 2006). Therefore, inflammatory responses in the cochlea must also be aimed at suppressing leukocyte migration and activation as well as promoting the clearance of apoptotic cells in the organ of Corti by non-professional phagocytes.

To the best of our knowledge, there is only one work exploring the presence of resolution mediators and receptors in the cochlea (Kalinec et al., 2009). Looking at the inner ear of guinea pigs, ANXA1 was localized in several cell populations lining the SM, particularly in Hensen cells of the organ of Corti (Kalinec et al., 2009). The majority of ANXA1 within cochlear Hensen cells was found stored inside lipid droplets, and experimental evidence suggests that it is 
released to the external milieu by a glucocorticoid-activated mechanism (Kalinec et al., 2009). ALX/FPR2, the receptor for ANXA1, LX A4/B4, RvD1/E1 as well as ATL and ATR, was also found expressed in the SM and cells lining the ST and the SV of the guinea pig cochlea, being particularly abundant in sensory IHCs and OHCs, Deiters and Pillar cells (Kalinec et al., 2009). It was speculated that ANXA1 released by Hensen cells could target these receptors to induce pro-resolution effects. Importantly, although low concentrations of LXA4 were detected, no evidence was found of glucocorticoid-induced release of LXA4 from any organ of Corti cells (Kalinec et al., 2009).

The absence of professional phagocytic cells during inflammatory responses in the SM and the organ of Corti supports the idea that supporting cells, working as non-professional phagocytes, would be responsible for clearing apoptotic hair cells (Abrashkin et al., 2006). However, the signals that mediate the clearance of dead organ of Corti cells are still unknown. Interestingly, ANXA1 has been implicated in promoting phagocytosis in two ways: by acting as an "eat me" signal on apoptotic cells (Arur et al., 2003) and as a receptor on the surface of professional and non-professional phagocytic cells to recognize exposed phosphatidylserine (PS) on cells undergoing apoptosis (Fan et al., 2004). It has been suggested that ANXA1 molecules might act as bridging proteins, linking apoptotic cells to neighbor cells, promoting the transformation of these adjacent cells into non-professional phagocytes, and then inducing the phagocytosis of the apoptotic cells (Fan et al., 2004). Thus, the massive release of ANXA1 from Hensen cells induced by glucocorticoids could be important for both stopping leukocyte migration into the SM and for facilitating the clearance of apoptotic hair cells by inducing the transformation of supporting cells in the organ of Corti to non-professional macrophages (Kalinec et al., 2009).

\section{Resolution of Inflammation and Drug-Related Hearing Loss}

Drug ototoxicity, defined as a temporary or permanent inner ear dysfunction after drug exposure, is one of the most preventable causes of deafness (Yorgason et al., 2011). While several classes of drugs are ototoxic, platinum-based chemotherapy agents (e.g., cisplatin) and aminoglycoside antibiotics (e.g., gentamicin, streptomycin) are known to induce irreversible hearing loss; others like macrolide antibiotics, antimalarial medications, loop diuretics and some NSAIDs are known to cause reversible inner ear toxicity (Yorgason et al., 2006). Although their ototoxicity is well known, these drugs are frequently used in the clinic because in many cases their benefits outweigh their negative side effects.

Here, we will only review cisplatin and aminoglycoside antibiotics since, as central components of many pharmacotherapies, they are arguably the most clinically relevant ototoxic drugs.

\section{Cisplatin}

Cisplatin is a potent chemotherapeutic agent used in the treatment of a variety of cancers. Its administration, however, is commonly associated with severe nephrotoxicity, peripheral neuropathy and ototoxicity (Coradini et al., 2007). The association of inflammation with cisplatin treatment has been suggested mostly by the beneficial effect of glucocorticoids on cisplatin ototoxicity (Murphy and Daniel, 2011; Parham, 2011), and the reduction of cisplatin nephrotoxicity by the pro-resolution mediators aspirin and adenosine (Okusa, 2002; Ramesh and Reeves, 2004).

In the inner ear the toxic effects of cisplatin are characterized by progressive, bilateral and irreversible hearing loss, preferentially affecting high frequencies and characterized essentially by damage to the cochlea (Nakai et al., 1982). The primary site of cochlear toxicity is the OHC, but IHCs, spiral ganglion neurons and stria vascularis cells are also affected. At the cellular level, cisplatin induces a complex network of events, including generation of ROS and activation of inflammatory cytokines and stress signaling pathways (Boulikas and Vougiouka, 2003; Rybak et al., 2007). These events eventually lead to cell death, mostly via induction of apoptosis (Boulikas and Vougiouka, 2003).

Currently, oxidative stress - not inflammation-is considered the major cause of cisplatin-induced hearing loss. However, the use of anti-oxidants as a single clinical strategy for cisplatininduced hearing loss is risky and many times ineffective, most likely because of the multiple physiological roles of ROS (discussed below, see "Anti-Oxidants" Section). On the other hand, cisplatin is able to induce endoplasmic reticulum stress in association with the unfolded-protein response (UPR; Mandic et al., 2003; Liu and Baliga, 2005; Yu et al., 2008), and UPR-triggered inflammation is now thought to be fundamental in the pathogenesis of several diseases (Zhang and Kaufman, 2008). Cisplatin is also known to induce apoptosis in proliferating cells by damaging the DNA through the formation of adducts (between different strands) and crosslinks (in the same strand). However, DNA damage could be less critical in cochlear hair cells, since they do not proliferate.

Using a proteomic approach in HeLa cells, it was demonstrated that cisplatin is able to change the expression of nuclear proteins as well as to induce alternative splicing (Wu et al., 2010; Zhang G. et al., 2012). Importantly, one of the proteins identified as changing its expression pattern was the pro-resolution mediator ANXA1, which was found to significantly increase its expression after cisplatin exposure. Moreover, it was shown that ANXA1 knockdown significantly increased cisplatin-induced DNA damage (Zhang G. et al., 2012), a response consistent with the up-regulation of ANXA1 in the cisplatin-resistant cell line CNE2-CDDP (Chow et al., 2009). These results suggest that ANXA1-based pharmacological strategies could protect against cisplatin-induced cell damage.

\section{Aminoglycoside Antibiotics}

Aminoglycosides are one of the most frequently employed antibiotics in the clinic. In addition to their potent bactericidal activities, aminoglycosides possess less bacterial resistance, more post-antibiotic effects and, perhaps most important, they are inexpensive. However, they have serious side effects, including nephrotoxicity and irreversible hearing loss (Forge and Schacht, 
2000). Although these drugs are most frequently used in ThirdWorld countries, where they usually are the only economically affordable antibiotics, their toxicity is also a problem in industrialized countries where they are not only used by the poorer segments of the society, but also in the treatment of cystic fibrosis (Prayle et al., 2016), in renal dialysis (Sowinski et al., 2008), and in emergencies. The World Health Organization recommends the use of aminoglycosides as part of the treatment against multidrug resistant tuberculosis (WHO, 2005).

It is generally accepted that, in vivo, aminoglycosides predominantly cross the BLB into the stria vascularis and, from there via marginal cells, into the endolymph (Li and Steyger, 2011). Once in the endolymph, these drugs would rapidly enter cochlear hair cells via mechanoelectrical transduction channels located on the stereocilia hair bundle, at their apical pole, and induce hair cell death (Marcotti et al., 2005; Alharazneh et al., 2011; Li and Steyger, 2011). Importantly, recent results suggest that inflammation boosts BLB permeability to aminoglycoside antibiotics, increasing the probability of drug-induced hearing loss (Koo et al., 2015). A number of studies in animal models, supported by studies in vitro, have established that ROS participate in the etiology of aminoglycoside-induced hearing loss (Forge and Schacht, 2000). From a clinical perspective, the more appealing result in support of this idea is the significant attenuation of gentamicin ototoxicity in humans by concurrent administration of aspirin detected in prospective, randomized, double-blind trials (Chen et al., 2007; Behnoud et al., 2009).

Another agent with recognized protective effects against aminoglycosides ototoxicity is the IGF1, a protein known to control cell proliferation, differentiation and apoptosis in various tissues and organs (Varela-Nieto et al., 2007). IGF1 is able to induce supporting cells in the mammalian organ of Corti to release the pro-resolution mediator netrin-1, which binds to one of its receptors (UNC5B) expressed on sensory hair cells and inhibits aminoglycoside-provoked apoptosis (Yamahara et al., 2017). Importantly, the efficacy of IGF1 in treating idiopathic sudden sensorineural hearing loss in humans has been confirmed in clinical trials (Nakagawa et al., 2010, 2014).

Based on the aforementioned studies, it is apparent that aminoglycoside-induced toxicity involves high oxidative stress and associated pathological signaling mechanisms like modulation of pro- and anti-apoptotic cell responses (Jiang et al., 2005). Thus, agents having strong antioxidant properties may have the ability to halt aminoglycosides' toxicity. However, as we discuss below, the use of anti-oxidants is a double-edge sword because ROS are important signaling molecules and intermediaries in triggering specific anti-inflammatory responses. The efficacy of aspirin and netrin-1, on the other hand, suggest that pro-resolving therapies could be the answer to prevention and/or amelioration of aminoglycoside ototoxicity.

\section{Resolution of Inflammation and Noise-Related Hearing Loss}

Although noise-related hearing loss (NRHL) remains associated with oxidative stress (Haase and Prasad, 2016), strong evidence suggest that inflammation is also a major contributor to this disorder. Several studies have demonstrated inflammatory responses in the cochlea following exposure to traumatic noise involving up-regulation of pro-inflammatory mediators and rapid recruitment of inflammatory cells from the vascular system (Derebery, 1996; Hirose et al., 2005; Fujioka et al., 2006; Tornabene et al., 2006; Tan et al., 2008; Wakabayashi et al., 2010). Within mere hours following acoustic overstimulation, leukocytes from the lateral wall and spiral limbus infiltrate the SV and the ST (Hirose et al., 2005; Sautter et al., 2006; Tornabene et al., 2006; Wakabayashi et al., 2010; Du et al., 2011), the SV side of the Reissner's membrane (Sautter et al., 2006), and the ST side of the basilar membrane (Tornabene et al., 2006; Yang et al., 2015; Figure 8); importantly, no phagocytic cells are usually found in the SM (Hirose et al., 2005; Sautter et al., 2006; Tornabene et al., 2006; Miyao et al., 2008; Du et al., 2011).

Several inflammation-related genes and proteins have been implicated in the cochlear response to noise (Fujioka et al., 2006; Kirkegaard et al., 2006; Tornabene et al., 2006; Shi and Nuttall, 2007; Yamamoto et al., 2009; Wakabayashi et al., 2010; Gratton et al., 2011; Nakamoto et al., 2012), yet the precise molecular mechanisms and the role of inflammation in the development of cochlear injury remain to be elucidated. One recent study reports an early increased expression and a latter peak of pro-inflammatory mediators in mice exposed to acute traumatic noise (Tan et al., 2016). The first peak was associated by the authors with the recruitment of inflammatory cells into the cochlea, whereas the second was related to reparative processes in response to cochlear damage. Chronic environmental noise exposure has also been linked to inflammatory processes in the cochlea (Tan et al., 2016). Interestingly, it was recently reported that a variable number of OHCs die immediately after exposure, while IHCs initially die in much smaller numbers but their death is spread out over days to months after noise exposure. Sometimes, noise damages supporting cells before sensory hair cells, and they may continue to degenerate for months after noise exposure (Bohne et al., 2017). It has been proposed that this delayed death of auditory cells is associated with inflammatory responses.

Since NRHL is frequently a predictable form of hearing loss, prevention through therapeutic intervention is feasible, and reduction or fast resolution of inflammation has the potential to be effective. The TNF- $\alpha$ inhibitor etanercept has been shown to reduce noise-induced threshold shifts in animals (Wang et al., 2003). Similarly, it was found that an anti-IL-6receptor antibody protected mice from NRHL (Wakabayashi et al., 2010). The anti-inflammatory and pro-resolution glucocorticoid dexamethasone (DEXA), delivered to the round window membrane, has also been shown to reduce hearing loss in patients after noise exposure (Zhou et al., 2013; Harrop-Jones et al., 2016).

Recent animal experiments have shown that noise exposure can lead to the degeneration of specific subsets of the nerve terminals in the ear without affecting thresholds (Kujawa and Liberman, 2009). This loss in synaptic ribbons, which could be the primary initial event in the degenerative cascade observed 
after noise, has been termed cochlear synaptopathy (Hickox et al., 2017; Liberman and Kujawa, 2017). Importantly, in addition to noise exposure, cochlear synaptopathy has also been associated with both aging (Sergeyenko et al., 2013; Altschuler et al., 2015; Möhrle et al., 2016) and the administration of ototoxic drugs (Bourien et al., 2014; Li et al., 2016). The confirmation of the presence of synaptopathy in human populations, and its potential association with inflammatory mechanisms, is currently under investigation (Hickox et al., 2017).

\section{Resolution of Inflammation and Age-Related Hearing Loss}

Although ARHL (aka presbycusis) is the most common form of hearing loss in adults, their cellular and molecular mechanisms are still poorly understood (Huang and Tang, 2010). ARHL is variably expressed, with large differences in hearing threshold levels and hearing disability between individuals (Davis, 1989). It is currently accepted that this variability is due to a combination of environmental and genetic factors (Uchida et al., 2011), further complicated by association with other forms of age-related morbidity including cardiovascular diseases (Hutchinson et al., 2010; Karpa et al., 2010), and dementia (Lin et al., 2011).

Another key contributor to several age-related diseases, including ARHL, is the state of chronic inflammation in the elderly known as "inflammaging" (Capri et al., 2006; Hunt et al., 2010; Leng et al., 2011; Baylis et al., 2013; Verschuur et al., 2014). Inflammaging is a consequence of immune-senescence, the aging of the immune system (Capri et al., 2006; Hunt et al., 2010). A potential link with inflammaging may be very important for ARHL, providing new approaches to prevent the development of this condition.

As a matter of fact, ARHL severity has already been linked to some factors associated with inflammation and inflammaging (Gates et al., 1993; Gates and Mills, 2005; Frisina et al., 2006; Verschuur et al., 2014). For instance, it has been shown that spiral ganglion cell damage can be caused by changes in the immune system (Iwai et al., 2003, 2008), while vascular and metabolic changes may affect the stria vascularis and, indirectly, cause inflammatory damage (Saitoh et al., 1995; Ohlemiller, 2009; Fetoni et al., 2011). In a clinical trial an association was found between serum immunoglobulin $G$ and hearing loss in individuals over 60 years of age (Lasisi et al., 2011). Thus, there is a high probability that inflammation and inflammaging could play a role in ARHL.

Studies in a mouse model of age-related sensory cell degeneration showed four major findings (Frye et al., 2017). First, it is mature, fully differentiated tissue macrophages that are the major type of macrophage populations responsible for the cochlear immune response in ARHL, and newly infiltrated monocytes are rare. Second, the mature tissue macrophages display a site-dependent change in their morphology and numbers and these changes are related to the dynamic progression of sensory cell degeneration. Third, apical and basal macrophages display different phenotypes under steady state conditions and have different response patterns to sensory cell degeneration. Finally, mature tissue macrophages are a sensitive internal sensor for early sensory cell degeneration.
Together, these results suggest that the macrophage-mediated immune response is an integral part of the cochlear response to age-related chronic sensory cell degeneration (Frye et al., 2017), and suggest that pro-resolution therapeutic intervention targeting macrophages could be important for ameliorating ARHL.

Importantly, a 3-year double-blind, randomized controlled trial, aimed at determining whether aspirin slows development or progression of ARHL, is currently being conducted in Australia (Lowthian et al., 2016).

\section{CURRENT AND POTENTIAL NEW CLINICAL STRATEGIES}

\section{Glucocorticoids}

The glucocorticoid DEXA has been shown to protect auditory hair cells against inflammatory cytokines by activating cell survival pathways (Haake et al., 2009). In addition, DEXA would be able to suppress drug toxicity associated with the production of free radicals by up-regulating antioxidant enzyme activity (Himeno et al., 2002; Paksoy et al., 2011). It was suggested that a single intratympanic injection of a DEXA solution administered immediately prior to cisplatin treatment had an otoprotective effect in rats (Daldal et al., 2007), and repeated intratympanic injections provided significant otoprotection when initially administered at the time of cisplatin treatment (Hill et al., 2008). In the clinic, however, inconsistent responses are commonly observed due to variable and limited exposure with aqueous solutions (Bird et al., 2007, 2011). Since DEXA is cleared rapidly from the middle ear down the Eustachian tube, it was suggested that a better clinical efficacy could be achieved by maintaining therapeutic drug levels for prolonged periods of time (Fernandez et al., 2016). It was recently reported that using a hydrogel containing DEXA (OTO-104) facilitates the presence of DEXA at therapeutic levels in the inner ear compartment for weeks to months in guinea pigs and sheep (Wang et al., 2009; Piu et al., 2011), and that a single intratympanic injection of 6\% OTO-104 almost completely protected guinea pigs from cisplatin ototoxicity (Fernandez et al., 2016).

As noted before, DEXA is known to work, at least in part, through the stimulation of synthesis and release of the pro-resolution mediator ANXA1. Thus, pharmacologic strategies based on ANXA1 or its synthetic peptides could be as effective as DEXA without its negative side effects.

\section{Anti-Oxidants}

Oxidative stress, a condition characterized by intracellular levels of ROS that impair the work of lipids, proteins and DNA, has been linked to many inner ear pathologies. Therefore, the use of anti-oxidants to diminish ROS levels appears as a no-brainer clinical strategy to protect the auditory function. However, ROS also work as mediators of many important physiological functions in a process termed redox biology (D’Autréaux and Toledano, 2007; Finkel, 2011; Schieber and Chandel, 2014). For example, mammalian cells respond to ROS by activating metabolic pathways that either provide 
cell stress protection or trigger cell apoptosis as a clearance mechanism for damaged tissues (Chen et al., 2009; Schieber and Chandel, 2014). Thus, ROS have two faces: redox biology, where ROS activate signaling pathways to initiate physiological processes, and oxidative stress where excessive amounts of intracellular ROS may lead to cell damage or death (Finkel, 2011; Schieber and Chandel, 2014). A critical point is that "low", "right", or "excessive" levels of ROS are not only celland tissue-dependent, but they are also associated with the physiological condition of the whole organism at the time of the pharmacological intervention. For instance, the balance between ROS and antioxidant defenses change during the reproductive process in mammals, with the high ROS levels required for appropriate fertilization, embryonic implantation, embryogenesis and placental development (Al-Gubory et al., 2010; Leghi and Muhlhausler, 2016) decreasing later on to diminish the risk of pregnancy disorders, including first trimester miscarriage (Jenkins et al., 2004), preeclampsia (D'Souza et al., 2016) and intrauterine growth restriction (Scifres and Nelson, 2009), associated with the excessive formation of reactive free radicals. In inflammation, significant evidence suggest that ROS are essential second messengers in innate and adaptive immune cells (West et al., 2011; Kamiński et al., 2013), but high levels of ROS aggravate inflammatory responses, resulting in tissue damage and different pathologies (Mittal et al., 2014). Therefore, while excessive levels of ROS are often directly responsible for cell death, their complete neutralization with antioxidant agents may be counterproductive by preventing the activation of natural cell defense mechanisms (Schieber and Chandel, 2014).

The association of ROS to cell and tissue protection mechanisms, such as optimal pathogen clearance, suggest that antioxidants should not be administered in healthy individuals that have a robust anti-oxidant defense and a healthy immune system. In addition, the timing of antioxidant treatment is crucial. This is certainly the case with patients in the intensive care unit, with multiple clinical trials consistently showing no efficacy or even increasing mortality in patients with critical illness that have been treated with antioxidants (Szakmany et al., 2012). Moreover, since different immune cell's subsets seems to have differential responses to ROS, it might be beneficial in the amelioration of cisplatin effects to increase a particular subset of $\mathrm{T}$ cells or macrophages by either increasing or decreasing ROS levels (Schieber and Chandel, 2014).

\section{Aspirin}

As already mentioned aspirin is a unique drug with, among others, anti-inflammatory, pro-resolution and anti-oxidant properties. Importantly, aspirin can work in combination with other drugs inducing a synergic effect. For example, it has been shown that aspirin has the potential to reduce the severity of cisplatin-induced side effects related to hearing and balance, by inducing several anti-inflammatory cytokines (Grilli et al., 1996; Yin et al., 1998). Thus, a combination of cisplatin and aspirin is an attractive strategy for managing solid tumors whilst protecting the auditory system. However, major obstacles in administering free-drug formulations include the definitive exposure to the targets of interest, individual pharmacokinetics and bio-distribution parameters. These factors are extremely difficult to control when drugs are individually administered. Recently, single pro-drugs containing a drug combination that can potentially overcome these challenges have been generated (Pathak et al., 2014). It is expected that a cisplatin + aspirin treatment in the form of a single pro-drug might increase efficiency and reduce ototoxic side effects of chemotherapy. A similar approach could be valid for reducing aminoglycosides ototoxicity, since aspirin is the only drug to date that has showed beneficial effect in clinical trials (Sha et al., 2006; Behnoud et al., 2009).

\section{Adenosine}

A role for adenosine in auditory function was suggested by experiments in frogs several decades ago (Bryant et al., 1987). Subsequent studies in chinchilla cochleae provided evidence that administration to rats of $R$-phenylisopropyladenosine $(R$ PIA), an agonist of the purinergic adenosine receptor A1AR, increased the activity of antioxidant enzymes and reduced lipid peroxidation (Ford et al., 1997a), while cisplatin exposure significantly increases the expression of adenosine receptors (Ford et al., 1997b). Studies in rats have also shown that RPIA protects cochlear explants from damage induced by cisplatin and noise (Hu et al., 1997; Hight et al., 2003). A potential role for adenosine in cochlear protection has been substantiated by more recent studies. For example, it has been shown that administration of adenosine amine congeners (ADAC) protect against noise-induced hearing loss (Vlajkovic et al., 2010), and elevation of adenosine levels protect against ARHL by inhibition of adenosine kinase (Vlajkovic et al., 2011). Furthermore, experimental results suggest that A1AR ameliorates cisplatin ototoxicity by inhibiting the NOX3/STAT1-mediated inflammatory pathway (Kaur et al., 2016).

Thus, drugs that increase the concentration of endogenous adenosine or directly activate adenosine receptors could play a pivotal role in the protection of the organ of Corti against cisplatin cytotoxicity. Once more, mediators of inflammatory resolution could serve as ideal targets for otoprotective therapies.

\section{CONCLUDING REMARKS}

Decades of intensive research have not delivered successful clinical strategies for preventing or ameliorating DRHL, NRHL or ARHL. Currently there is not a single specific, FDA-approved otoprotective agent. In addition, the most common therapeutic approaches, glucocorticoid and antioxidants, produce inconsistent results. Thus, we feel that an alternative research paradigm is absolutely needed to break the stalemate.

The typical research approach has been, and still is, to look for prevention of cell damage induced by the toxic agents under investigation. Although this approach is reasonable and absolutely valid, we want to propose an alternative way: enhance the physiological mechanisms designed for our 
organism for dealing with toxic agents, looking for an accelerated and improved cell and tissue protection, healing and repair. Specifically, we propose to select the pro-resolution pathways associated with the successful termination of inflammatory responses as a new target for research aimed at preventing or ameliorating DRHL, NRHL and ARHL. We strongly believe that improving the resolution of cochlear inflammatory responses is one way, although most likely not the only one, to overcome the current impasse in this important area of hearing research.

Inflammation is a beneficial host reaction aimed at protecting individuals from infections and tissue injury. Uncontrolled inflammation, however, is now widely recognized as a common factor in many diseases and organ dysfunctions, including DRHL, NRHL and ARHL. Since inflammatory responses are aimed to eliminate invading organisms and repair injured tissues, they are naturally self-limited. Resolution, as the last step in any inflammatory response, is exquisitely regulated, and it is completed only after any potential for continuous tissue damage has been conquered. Thus, improving the resolution phase of inflammatory responses in the inner ear may naturally result in cell protection, tissue healing and repair, therefore contributing to the prevention or amelioration of auditory dysfunctions.

The success of the proposed approach is heavily dependent on the full understanding of resolution biology and the expression and function of pro-resolution mediators and receptors in the mammalian cochlea. Unfortunately, the current number of studies on this topic in the inner ear is clearly insufficient. Therefore, we consider imperative to accelerate the identification

\section{REFERENCES}

Abrashkin, K. A., Izumikawa, M., Miyazawa, T., Wang, C. H., Crumling, M. A., Swiderski, D. L., et al. (2006). The fate of outer hair cells after acoustic or ototoxic insults. Hear. Res. 218, 20-29. doi: 10.1016/j.heares.2006. 04.001

Aherne, C. M., Collins, C. B., Masterson, J. C., Tizzano, M., Boyle, T. A., Westrich, J. A., et al. (2012). Neuronal guidance molecule netrin-1 attenuates inflammatory cell trafficking during acute experimental colitis. Gut 61, 695-705. doi: 10.1136/gutjnl-2011-300012

Aherne, C. M., Kewley, E. M., and Eltzschig, H. K. (2011). The resurgence of A2B adenosine receptor signaling. Biochim. Biophys. Acta 1808, 1329-1339. doi: 10.1016/j.bbamem.2010.05.016

Alessandri, A. L., Sousa, L. P., Lucas, C. D., Rossi, A. G., Pinho, V., and Teixeira, M. M. (2013). Resolution of inflammation: mechanisms and opportunity for drug development. Pharmacol. Ther. 139, 189-212. doi: 10.1016/j.pharmthera.2013.04.006

Al-Gubory, K. H., Fowler, P. A., and Garrel, C. (2010). The roles of cellular reactive oxygen species, oxidative stress and antioxidants in pregnancy outcomes. Int. J. Biochem. Cell Biol. 42, 1634-1650. doi: 10.1016/j.biocel. 2010.06.001

Alharazneh, A., Luk, L., Huth, M., Monfared, A., Steyger, P. S., Cheng, A. G., et al. (2011). Functional hair cell mechanotransducer channels are required for aminoglycoside ototoxicity. PLoS One 6:e22347. doi: 10.1371/journal.pone. 0022347

Altschuler, R. A., Dolan, D. F., Halsey, K., Kanicki, A., Deng, N., Martin, C., et al. (2015). Age-related changes in auditory nerve-inner hair cell connections, hair cell numbers, auditory brain stem response and gap detection in UM-HET4 mice. Neuroscience 292, 22-33. doi: 10.1016/j.neuroscience.2015. 01.068 of all pro-resolution pathways at work in the cochlea. Next, their specific functions should be explored to understand how to enhance, safely and rapidly, the resolution of inflammatory responses in the inner ear. Of course, we are not proposing to eliminate any of the current research strategies, since it is unlikely that any single approach will be the magic bullet for all non-resolving, chronic inflammatory and autoimmune diseases. Most likely combinatorial pro-resolving therapies also including, perhaps, dietary $\mathrm{w}-3$ and $\mathrm{w}-6$ essential fatty acids and inhibitors of specific pro-inflammatory agents and their receptors, would be necessary to obtain significant effects. Regardless, we are convinced that the elucidation of the mechanisms of pharmacological modulation of the resolution process would be crucial to finding the most effective therapeutic agents for preventing or ameliorating DRHL, NRHL and ARHL.

\section{AUTHOR CONTRIBUTIONS}

FK saw the need of a review on this topic. GMK and GL reviewed the literature and organized the information. RAU and FK wrote the manuscript.

\section{FUNDING}

This work was supported by the National Institutes of Health (grant DK52913), the Department of Head and Neck Surgery, David Geffen School of Medicine at UCLA and Mayo Foundation funds. The content of this work is solely the responsibility of the authors and does not necessarily represent the official views of these Institutions.

Anong, W. A., Franco, T., Chu, H., Weis, T. L., Devlin, E. E., Bodine, D. M. et al. (2009). Adducin forms a bridge between the erythrocyte membrane and its cytoskeleton and regulates membrane cohesion. Blood 114, 1904-1912. doi: 10.1182/blood-2009-02-203216

Ariel, A., Fredman, G., Sun, Y. P., Kantarci, A., Van Dyke, T. E., Luster, A. D., et al. (2006). Apoptotic neutrophils and T cells sequester chemokines during immune response resolution through modulation of CCR5 expression. Nat. Immunol. 7, 1209-1216. doi: 10.1038/ni1392

Arita, M., Bianchini, F., Aliberti, J., Sher, A., Chiang, N., Hong, S., et al. (2005). Stereochemical assignment, antiinflammatory properties, and receptor for the omega-3 lipid mediator resolvin E1. J. Exp. Med. 201, 713-722. doi: $10.1084 /$ jem. 20042031

Arur, S., Uche, U. E., Rezaul, K., Fong, M., Scranton, V., Cowan, A. E., et al. (2003). Annexin $\mathrm{I}$ is an endogenous ligand that mediates apoptotic cell engulfment. Dev. Cell 4, 587-598. doi: 10.1016/s1534-5807(03)00090-x

Backhouse, S., Coleman, B., and Shepherd, R. (2008). Surgical access to the mammalian cochlea for cell-based therapies. Exp. Neurol. 214, 193-200. doi: 10.1016/j.expneurol.2008.08.002

Bandeira-Melo, C., Bozza, P. T., Diaz, B. L., Cordeiro, R. S., Jose, P. J., Martins, M. A., et al. (2000). Cutting edge: lipoxin (LX) A4 and aspirin-triggered 15-epi-LXA4 block allergen-induced eosinophil trafficking. J. Immunol. 164, 2267-2271. doi: 10.4049/jimmunol.164.5.2267

Barnig, C., Cernadas, M., Dutile, S., Liu, X., Perrella, M. A., Kazani, S., et al. (2013). Lipoxin A4 regulates natural killer cell and type 2 innate lymphoid cell activation in asthma. Sci. Transl. Med. 5:174ra126. doi: 10.1126/scitranslmed. 3004812

Baylis, D., Bartlett, D. B., Syddall, H. E., Ntani, G., Gale, C. R., Cooper, C., et al. (2013). Immune-endocrine biomarkers as predictors of frailty and mortality: a 10-year longitudinal study in community-dwelling older people. Age Dordr. 35, 963-971. doi: 10.1007/s11357-012-9396-8 
Behnoud, F., Davoudpur, K., and Goodarzi, M. T. (2009). Can aspirin protect or at least attenuate gentamicin ototoxicity in humans? Saudi Med. J. 30, 1165-1169.

Bena, S., Brancaleone, V., Wang, J. M., Perretti, M., and Flower, R. J. (2012). Annexin A1 interaction with the FPR2/ALX receptor: identification of distinct domains and downstream associated signaling. J. Biol. Chem. 287, 24690-24697. doi: 10.1074/jbc.M112.377101

Bird, P. A., Begg, E. J., Zhang, M., Keast, A. T., Murray, D. P., and Balkany, T. J. (2007). Intratympanic versus intravenous delivery of methylprednisolone to cochlear perilymph. Otol. Neurotol. 28, 1124-1130. doi: 10.1097/mao. 0b013e31815aee21

Bird, P. A., Murray, D. P., Zhang, M., and Begg, E. J. (2011). Intratympanic versus intravenous delivery of dexamethasone and dexamethasone sodium phosphate to cochlear perilymph. Otol. Neurotol. 32, 933-936. doi: 10.1097/MAO. 0b013e3182255933

Blidner, A. G., Méndez-Huergo, S. P., Cagnoni, A. J., and Rabinovich, G. A. (2015). Re-wiring regulatory cell networks in immunity by galectin-glycan interactions. FEBS Lett. 589, 3407-3418. doi: 10.1016/j.febslet.2015.08.037

Bohne, B. A., Kimlinger, M., and Harding, G. W. (2017). Time course of organ of Corti degeneration after noise exposure. Hear. Res. 344, 158-169. doi: 10.1016/j.heares.2016.11.009

Bonnans, C., Fukunaga, K., Levy, M. A., and Levy, B. D. (2006). Lipoxin $A_{4}$ regulates bronchial epithelial cell responses to acid injury. Am. J. Pathol. 168, 1064-1072. doi: 10.2353/ajpath.2006.051056

Bonnans, C., Vachier, I., Chavis, C., Godard, P., Bousquet, J., and Chanez, P. (2002). Lipoxins are potential endogenous antiinflammatory mediators in asthma. Am. J. Respir. Crit. Care Med. 165, 1531-1535. doi: 10.1164/rccm. 200201-053oc

Boulikas, T., and Vougiouka, M. (2003). Cisplatin and platinum drugs at the molecular level. (Review). Oncol. Rep. 10, 1663-1682. doi: 10.3892/or.10.6.1663

Bourien, J., Tang, Y., Batrel, C., Huet, A., Lenoir, M., Ladrech, S., et al. (2014). Contribution of auditory nerve fibers to compound action potential of the auditory nerve. J. Neurophysiol. 112, 1025-1039. doi: 10.1152/jn. 00738.2013

Bours, M. J., Swennen, E. L., Di Virgilio, F., Cronstein, B. N., and Dagnelie, P. C. (2006). Adenosine $5^{\prime}$-triphosphate and adenosine as endogenous signaling molecules in immunity and inflammation. Pharmacol. Ther. 112, 358-404. doi: 10.1016/j.pharmthera.2005.04.013

Brancaleone, V., Dalli, J., Bena, S., Flower, R. J., Cirino, G., and Perretti, M. (2011). Evidence for an anti-inflammatory loop centered on polymorphonuclear leukocyte formyl peptide receptor 2/lipoxin A4 receptor and operative in the inflamed microvasculature. J. Immunol. 186, 4905-4914. doi: 10.4049/jimmunol.1003145

Brancaleone, V., Mitidieri, E., Flower, R. J., Cirino, G., and Perretti, M. (2014). Annexin A1 mediates hydrogen sulfide properties in the control of inflammation. J. Pharmacol. Exp. Ther. 351, 96-104. doi: 10.1124/jpet.114. 217034

Brüne, B. (2005). The intimate relation between nitric oxide and superoxide in apoptosis and cell survival. Antioxid. Redox Signal. 7, 497-507. doi: 10.1089/ars. 2005.7.497

Bryant, G. M., Barron, S. E., Norris, C. H., and Guth, P. S. (1987). Adenosine is a modulator of hair cell-afferent neurotransmission. Hear. Res. 30, 231-237. doi: 10.1016/0378-5955(87)90139-0

Campbell, E. L., Louis, N. A., Tomassetti, S. E., Canny, G. O., Arita, M., Serhan, C. N., et al. (2007). Resolvin E1 promotes mucosal surface clearance of neutrophils: a new paradigm for inflammatory resolution. FASEB J. 21, 3162-3170. doi: 10.1096/fj.07-8473com

Capri, M., Monti, D., Salvioli, S., Lescai, F., Pierini, M., Altilia, S., et al. (2006). Complexity of anti-immunosenescence strategies in humans. Artif. Organs 30, 730-742. doi: 10.1111/j.1525-1594.2006.00295.x

Cash, J. L., Hart, R., Russ, A., Dixon, J. P., Colledge, W. H., Doran, J., et al. (2008). Synthetic chemerin-derived peptides suppress inflammation through ChemR23. J. Exp. Med. 205, 767-775. doi: 10.1084/jem.200 71601

Caye-Thomasen, P., Worsoe, L., Brandt, C. T., Miyazaki, H., Ostergaard, C., Frimodt-Moller, N., et al. (2009). Routes, dynamics and correlates of cochlear inflammation in terminal and recovering experimental meningitis. Laryngoscope 119, 1560-1570. doi: 10.1002/lary.20260
Chen, Y., Azad, M. B., and Gibson, S. B. (2009). Superoxide is the major reactive oxygen species regulating autophagy. Cell Death Differ. 16, 1040-1052. doi: $10.1038 /$ cdd.2009.49

Chen, Y., Huang, W. G., Zha, D. J., Qiu, J. H., Wang, J. L., Sha, S. H., et al. (2007). Aspirin attenuates gentamicin ototoxicity: from the laboratory to the clinic. Hear. Res. 226, 178-182. doi: 10.1016/j.heares.2006.05.008

Chiang, N., Arita, M., and Serhan, C. N. (2005). Anti-inflammatory circuitry: lipoxin, aspirin-triggered lipoxins and their receptor ALX. Prostaglandins Leukot. Essent. Fatty Acids 73, 163-177. doi: 10.1016/j.plefa. 2005.05.003

Chiang, N., Bermudez, E. A., Ridker, P. M., Hurwitz, S., and Serhan, C. N. (2004). Aspirin triggers antiinflammatory 15-epi-lipoxin A4 and inhibits thromboxane in a randomized human trial. Proc. Natl. Acad. Sci. U S A 101, 15178-15183. doi: 10.1073/pnas.0405445101

Chiang, N., Dalli, J., Colas, R. A., and Serhan, C. N. (2015). Identification of resolvin D2 receptor mediating resolution of infections and organ protection. J. Exp. Med. 212, 1203-1217. doi: 10.1084/jem.20150225

Chiang, N., Fredman, G., Bäckhed, F., Oh, S. F., Vickery, T., Schmidt, B. A. et al. (2012). Infection regulates pro-resolving mediators that lower antibiotic requirements. Nature 484, 524-528. doi: 10.1038/nature11042

Chiang, N., Serhan, C. N., Dahlén, S. E., Drazen, J. M., Hay, D. W., Rovati, G. E., et al. (2006). The lipoxin receptor ALX: potent ligand-specific and stereoselective actions in vivo. Pharmacol. Rev. 58, 463-487. doi: 10.1124/ pr.58.3.4

Chiang, N., Shinohara, M., Dalli, J., Mirakaj, V., Kibi, M., Choi, A. M., et al. (2013). Inhaled carbon monoxide accelerates resolution of inflammation via unique proresolving mediator-heme oxygenase-1 circuits. J. Immunol. 190, 6378-6388. doi: 10.4049/jimmunol.1202969

Chinetti, G., Fruchart, J. C., and Staels, B. (2003). Peroxisome proliferatoractivated receptors and inflammation: from basic science to clinical applications. Int. J. Obes. Relat. Metab. Disord. 27, S41-S45. doi: 10.1038/sj.ijo. 0802499

Chow, B. H., Chua, D. T., Sham, J. S., Zhang, M. Y., Chow, L. W., Bi, J., et al. (2009). Increased expression of annexin I is associated with drug-resistance in nasopharyngeal carcinoma and other solid tumors. Proteomics Clin. Appl. 3, 654-662. doi: 10.1002/prca.200800164

Clish, C. B., Levy, B. D., Chiang, N., Tai, H. H., and Serhan, C. N. (2000). Oxidoreductases in lipoxin A4 metabolic inactivation: a novel role for 15-onoprostaglandin 13-reductase/leukotriene B4 12-hydroxydehydrogenase in inflammation. J. Biol. Chem. 275, 25372-25380. doi: 10.1074/jbc. M002863200

Coradini, P. P., Cigana, L., Selistre, S. G., Rosito, L. S., and Brunetto, A. L. (2007). Ototoxicity from cisplatin therapy in childhood cancer. J. Pediatr. Hematol. Oncol. 29, 355-360. doi: 10.1097/mph.0b013e318059c220

Cronstein, B. N., Montesinos, M. C., and Weissmann, G. (1999). Sites of action for future therapy: an adenosine-dependent mechanism by which aspirin retains its antiinflammatory activity in cyclooxygenase- 2 and NFкB knockout mice. Osteoarthr. Cartil. 7, 361-363. doi: 10.1053/joca.19 98.0236

Csóka, B., Selmeczy, Z., Koscsó, B., Németh, Z. H., Pacher, P., Murray, P. J., et al. (2012). Adenosine promotes alternative macrophage activation via $A_{2 A}$ and $\mathrm{A}_{2 \mathrm{~B}}$ receptors. FASEB J. 26, 376-386. doi: 10.1096/fj.11-190934

D'Acquisto, F., Perretti, M., and Flower, R. J. (2008). Annexin-A1: a pivotal regulator of the innate and adaptive immune systems. Br. J. Pharmacol. 155, 152-169. doi: 10.1038/bjp.2008.252

Daldal, A., Odabasi, O., and Serbetcioglu, B. (2007). The protective effect of intratympanic dexamethasone on cisplatin-induced ototoxicity in guinea pigs. Otolaryngol. Head Neck Surg. 137, 747-752. doi: 10.1016/j.otohns.2007.05.068

Dalli, J., Chiang, N., and Serhan, C. N. (2014). Identification of 14-series sulfido-conjugated mediators that promote resolution of infection and organ protection. Proc. Natl. Acad. Sci. U S A 111, E4753-E4761. doi: 10.1073/pnas. 1415006111

Dalli, J., Chiang, N., and Serhan, C. N. (2015a). Elucidation of novel 13-series resolvins that increase with atorvastatin and clear infections. Nat. Med. 21, 1071-1075. doi: 10.1038/nm.3911

Dalli, J., Ramon, S., Norris, P. C., Colas, R. A., and Serhan, C. N. (2015b). Novel proresolving and tissue-regenerative resolvin and protectin sulfido-conjugated pathways. FASEB J. 29, 2120-2136. doi: 10.1096/fj.14-268441 
Dalli, J., Colas, R. A., and Serhan, C. N. (2013a). Novel n-3 immunoresolvents: structures and actions. Sci. Rep. 3:1940. doi: 10.1038/srep06726

Dalli, J., Winkler, J. W., Colas, R. A., Arnardottir, H., Cheng, C. Y., Chiang, N., et al. (2013b). Resolvin D3 and aspirin-triggered resolvin D3 are potent immunoresolvents. Chem. Biol. 20, 188-201. doi: 10.1016/j.chembiol. 2012.11.010

D'Autréaux, B., and Toledano, M. B. (2007). ROS as signalling molecules: mechanisms that generate specificity in ROS homeostasis. Nat. Rev. Mol. Cell Biol. 8, 813-824. doi: 10.1038/nrm2256

Davis, A. C. (1989). The prevalence of hearing impairment and reported hearing disability among adults in Great Britain. Int. J. Epidemiol. 18, 911-917. doi: $10.1093 / \mathrm{ije} / 18.4 .911$

Decker, Y., McBean, G., and Godson, C. (2009). Lipoxin $A_{4}$ inhibits IL-1 $\beta$ induced IL-8 and ICAM-1 expression in 1321N1 human astrocytoma cells. Am. J. Physiol. Cell Physiol. 296, C1420-C1427. doi: 10.1152/ajpcell.00380.2008

Derebery, M. J. (1996). Allergic and immunologic aspects of Meniere's disease. Otolaryngol. Head Neck Surg. 114, 360-365. doi: 10.1016/s01945998(96)70204-8

Dias-Baruffi, M., Zhu, H., Cho, M., Karmakar, S., McEver, R. P., and Cummings, R. D. (2003). Dimeric galectin-1 induces surface exposure of phosphatidylserine and phagocytic recognition of leukocytes without inducing apoptosis. J. Biol. Chem. 278, 41282-41293. doi: 10.1074/jbc.M306624200

Dona, M., Fredman, G., Schwab, J. M., Chiang, N., Arita, M., Goodarzi, A., et al. (2008). Resolvin E1, an EPA-derived mediator in whole blood, selectively counterregulates leukocytes and platelets. Blood 112, 848-855. doi: 10.1182/blood-2007-11-122598

D'Souza, V., Rani, A., Patil, V., Pisal, H., Randhir, K., Mehendale, S., et al. (2016). Increased oxidative stress from early pregnancy in women who develop preeclampsia. Clin. Exp. Hypertens. 38, 225-232. doi: 10.3109/10641963.2015. 1081226

Du, X., Choi, C. H., Chen, K., Cheng, W., Floyd, R. A., and Kopke, R. D. (2011). Reduced formation of oxidative stress biomarkers and migration of mononuclear phagocytes in the cochleae of chinchilla after antioxidant treatment in acute acoustic trauma. Int. J. Otolaryngol. 2011:612690. doi: 10.1155/2011/612690

Du, X.-Y., and Leung, L. L. K. (2009). Proteolytic regulatory mechanism of chemerin bioactivity. Acta Biochim. Biophys. Sin. (Shanghai) 41, 973-979. doi: 10.1093/abbs/gmp091

Duffin, R., Leitch, A. E., Fox, S., Haslett, C., and Rossi, A. G. (2010). Targeting granulocyte apoptosis: mechanisms, models and therapies. Immunol. Rev. 236, 28-40. doi: 10.1111/j.1600-065X.2010.00922.x

Duvall, M. G., and Levy, B. D. (2016). DHA- and EPA-derived resolvins, protectins, and maresins in airway inflammation. Eur. J. Pharmacol. 785, 144-155. doi: 10.1016/j.ejphar.2015.11.001

Fan, X., Krahling, S., Smith, D., Williamson, P., and Schlegel, R. A. (2004). Macrophage surface expression of annexins I and II in the phagocytosis of apoptotic lymphocytes. Mol. Biol. Cell 15, 2863-2872. doi: 10.1091/mbc.e0309-0670

Farnworth, S. L., Henderson, N. C., Mackinnon, A. C., Atkinson, K. M., Wilkinson, T., Dhaliwal, K., et al. (2008). Galectin-3 reduces the severity of pneumococcal pneumonia by augmenting neutrophil function. Am. J. Pathol. 172, 395-405. doi: 10.2353/ajpath.2008.070870

Fernandez, R., Harrop-Jones, A., Wang, X., Dellamary, L., LeBel, C., and Piu, F. (2016). The sustained-exposure dexamethasone formulation OTO-104 offers effective protection against cisplatin-induced hearing loss. Audiol. Neurootol. 21, 22-29. doi: 10.1159/000441833

Fetoni, A. R., Picciotti, P. M., Paludetti, G., and Troiani, D. (2011). Pathogenesis of presbycusis in animal models: a review. Exp. Gerontol. 46, 413-425. doi: 10.1016/j.exger.2010.12.003

Finkel, T. (2011). Signal transduction by reactive oxygen species. J. Cell Biol. 194, 7-15. doi: 10.1083/jcb.201102095

Fiore, S., Maddox, J. F., Perez, H. D., and Serhan, C. N. (1994). Identification of a human cDNA encoding a functional high affinity lipoxin A4 receptor. J. Exp. Med. 180, 253-260. doi: 10.1084/jem.180.1.253

Ford, M. S., Maggirwar, S. B., Rybak, L. P., Whitworth, C., and Ramkumar, V. (1997a). Expression and function of adenosine receptors in the chinchilla cochlea. Hear. Res. 105, 130-140. doi: 10.1016/s0378-5955(96) 00204-3
Ford, M. S., Nie, Z., Whitworth, C., Rybak, L. P., and Ramkumar, V. (1997b). Up-regulation of adenosine receptors in the cochlea by cisplatin. Hear. Res. 111, 143-152. doi: 10.1016/s0378-5955(97)00103-2

Forge, A., and Schacht, J. (2000). Aminoglycoside antibiotics. Audiol. Neurootol. 5, 3-22. doi: 10.1159/000013861

Frisina, S. T., Mapes, F., Kim, S., Frisina, D. R., and Frisina, R. D. (2006). Characterization of hearing loss in aged type II diabetics. Hear. Res. 211, 103-113. doi: 10.1016/j.heares.2005.09.002

Frye, M. D., Yang, W., Zhang, C., Xiong, B., and Hu, B. H. (2017). Dynamic activation of basilar membrane macrophages in response to chronic sensory cell degeneration in aging mouse cochleae. Hear. Res. 344, 125-134. doi: 10.1016/j. heares.2016.11.003

Fujioka, M., Kanzake, S., Okano, H. J., Masuda, M., Ogawa, K., and Okano, H. (2006). Proinflammatory cytokines expression in noise-induced damaged cochlea. J. Neurosci. Res. 83, 575-583. doi: 10.1002/jnr.20764

Fujioka, M., Okano, H., and Ogawa, K. (2014). Inflammatory and immune responses in the cochlea: potential therapeutic targets for sensorineural hearing loss. Front. Pharmacol. 5:287. doi: 10.3389/fphar. 2014.00287

Garg, A. D., Nowis, D., Golab, J., Vandenabeele, P., Krysko, D. V., and Agostinis, P. (2010). Immunogenic cell death, DAMPs and anticancer therapeutics: an emerging amalgamation. Biochim. Biophys. Acta 1805, 53-71. doi: 10.1016/j. bbcan.2009.08.003

Gates, G. A., Cobb, J. L., D’Agostino, R. B., and Wolf, P. A. (1993). The relation of hearing in the elderly to the presence of cardiovascular disease and cardiovascular risk factors. Arch. Otolaryngol. Head Neck Surg. 119, 156-161. doi: 10.1001/archotol.1993.01880140038006

Gates, G. A., and Mills, J. H. (2005). Presbycusis. Lancet 366, 1111-1120. doi: 10.1016/S0140-6736(05)67423-5

Gillespie, L. N., Marzella, P. L., Clark, G. M., and Crook, J. M. (2005). Netrin1 as a guidance molecule in the postnatal rat cochlea. Hear. Res. 199, 117-123. doi: 10.1016/j.heares.2004.07.004

Gilroy, D. W. (2005a). New insights into the anti-inflammatory actions of aspirininduction of nitric oxide through the generation of epi-lipoxins. Mem. Inst. Oswaldo. Cruz 100, 49-54. doi: 10.1590/s0074-02762005000900009

Gilroy, D. W. (2005b). The role of aspirin-triggered lipoxins in the mechanism of action of aspirin. Prostaglandins Leukot. Essent. Fatty Acids 73, 203-210. doi: 10.1016/j.plefa.2005.05.007

Gilroy, D. W., Colville-Nash, P. R., Willis, D., Chivers, J., Paul-Clark, M. J., and Willoughby, D. A. (1999). Inducible cyclooxygenase may have anti-inflammatory properties. Nat. Med. 5, 698-701. doi: 10.1038/9550

Gilroy, D., and De Maeyer, R. (2015). New insights into the resolution of inflammation. Semin. Immunol. 27, 161-168. doi: 10.1016/j.smim. 2015.05.003

Gilroy, D. W., Lawrence, T., Perretti, M., and Rossi, A. G. (2004). Inflammatory resolution: new opportunities for drug discovery. Nat. Rev. Drug Discov. 3 , 401-416. doi: $10.1038 / \mathrm{nrd} 1383$

Gilroy, D. W., and Perretti, M. (2005). Aspirin and steroids: new mechanistic findings and avenues for drug discovery. Curr. Opin. Pharmacol. 5, 405-411. doi: 10.1016/j.coph.2005.02.006

Gloddek, B., Lassmann, S., Gloddek, J., and Arnold, W. (1999). Role of S- $100 \beta$ as potential autoantigen in an autoimmune disease of the inner ear. J. Neuroimmunol. 101, 39-46. doi: 10.1016/s0165-5728(99)00131-9

Gonzalez-Períz, A., and Claria, J. (2007). New approaches to the modulation of the cyclooxygenase-2 and 5-lipoxygenase pathways. Curr. Top. Med. Chem. 7, 297-309. doi: 10.2174/156802607779941378

Goubern, M., Andriamihaja, M., Nübel, T., Blachier, F., and Bouillaud, F. (2007). Sulfide, the first inorganic substrate for human cells. FASEB J. 21, 1699-1706. doi: 10.1096/fj.06-7407com

Gratton, M. A., Eleftheriadou, A., Garcia, J., Verduzco, E., Martin, G. K., Lonsbury-Martin, B. L., et al. (2011). Noise-induced changes in gene expression in the cochleae of mice differing in their susceptibility to noise damage. Hear. Res. 277, 211-226. doi: 10.1016/j.heares.2010.12.014

Green, D. R., Ferguson, T., Zitvogel, L., and Kroemer, G. (2009). Immunogenic and tolerogenic cell death. Nat. Rev. Immunol. 9, 353-363. doi: 10.1038/nri2545

Grilli, M., Pizzi, M., Memo, M., and Spano, P. (1996). Neuroprotection by aspirin and sodium salicylate through blockade of NF-кB activation. Science 274, 1383-1385. doi: $10.1126 /$ science. 274.5291 .1383 
Grumbach, Y., Quynh, N. V., Chiron, R., and Urbach, V. (2009). LXA4 stimulates ZO-1 expression and transepithelial electrical resistance in human airway epithelial (16HBE14o-) cells. Am. J. Physiol. Lung Cell. Mol. Physiol. 296, L101-L108. doi: 10.1152/ajplung.00018.2008

Haake, S. M., Dinh, C. T., Chen, S., Eshraghi, A. A., and Van De Water, T. R. (2009). Dexamethasone protects auditory hair cells against TNF $\alpha$-initiated apoptosis via activation of PI3K/Akt and NFKB signaling. Hear. Res. 255, 22-32. doi: 10.1016/j.heares.2009.05.003

Haase, G. M., and Prasad, K. N. (2016). Oxidative damage and inflammation biomarkers: strategy in hearing disorders. Otol. Neurotol. 37, e303-e308. doi: 10.1097/MAO.0000000000001072

Hallett, J. M., Leitch, A. E., Riley, N. A., Duffin, R., Haslett, C., and Rossi, A. G. (2008). Novel pharmacological strategies for driving inflammatory cell apoptosis and enhancing the resolution of inflammation. Trends Pharmacol. Sci. 29, 250-257. doi: 10.1016/j.tips.2008.03.002

Harris, J. P. (1983). Immunology of the inner ear: response of the inner ear to antigen challenge. Otolaryngol. Head Neck Surg. 91, 18-32. doi: $10.1177 / 019459988309100105$

Harris, J. P. (1984). Immunology of the inner ear: evidence of local antibody production. Ann. Otol. Rhinol. Laryngol. 93, 157-162. doi: 10.1177/000348948409300211

Harrop-Jones, A., Wang, X., Fernandez, R., Dellamary, L., Ryan, A. F., LeBel, C., et al. (2016). The sustained-exposure dexamethasone formulation OTO-104 offers effective protection against noise-induced hearing loss. Audiol. Neurootol. 21, 12-21. doi: 10.1159/000441814

Haskó, G., and Cronstein, B. (2013). Regulation of inflammation by adenosine. Front. Immunol. 4:85. doi: 10.3389/fimmu.2013.00085

Haskó, G., and Cronstein, B. N. (2004). Adenosine: an endogenous regulator of innate immunity. Trends Immunol. 25, 33-39. doi: 10.1016/j.it.2003.11.003

Hayashi, Y., Yamamoto, N., Nakagawa, T., and Ito, J. (2014). Insulin-like growth factor 1 induces the transcription of Gap43 and Ntn1 during hair cell protection in the neonatal murine cochlea. Neurosci. Lett. 560, 7-11. doi: 10.1016/j.neulet. 2013.11.062

Headland, S. E., and Norling, L. V. (2015). The resolution of inflammation: principles and challenges. Semin. Immunol. 27, 149-160. doi: 10.1016/j.smim. 2015.03.014

Henderson, N. C., and Sethi, T. (2009). The regulation of inflammation by galectin-3. Immunol. Rev. 230, 160-171. doi: 10.1111/j.1600-065x.2009. 00794.x

Hickox, A. E., Larsen, E., Heinz, M. G., Shinobu, L., and Whitton, J. P. (2017). Translational issues in cochlear synaptopathy. Hear. Res. 349, 164-171. doi: 10.1016/j.heares.2016.12.010

Hight, N. G., McFadden, S. L., Henderson, D., Burkard, R. F., and Nicotera, T. (2003). Noise-induced hearing loss in chinchillas pre-treated with glutathione monoethylester and R-PIA. Hear. Res. 179, 21-32. doi: 10.1016/s03785955(03)00067-4

Hill, G. W., Morest, D. K., and Parham, K. (2008). Cisplatin-induced ototoxicity: effect of intratympanic dexamethasone injections. Otol. Neurotol. 29, 1005-1011. doi: 10.1097/MAO.0b013e31818599d5

Himeno, C., Komeda, M., Izumikawa, M., Takemura, K., Yagi, M., Weiping, Y., et al. (2002). Intra-cochlear administration of dexamethasone attenuates aminoglycoside ototoxicity in the guinea pig. Hear. Res. 167, 61-70. doi: 10.1016/s0378-5955(02)00345-3

Hirose, K., Discolo, C. M., Keasler, J. R., and Ransohoff, R. (2005). Mononuclear phagocytes migrate into the murine cochlea after acoustic trauma. J. Comp. Neurol. 489, 180-194. doi: 10.1002/cne.20619

Hirose, K., and Liberman, M. C. (2003). Lateral wall histopathology and endocochlear potential in the noise-damaged mouse cochlea. J. Assoc. Res. Otolaryngol. 4, 339-352. doi: 10.1007/s10162-002-3036-4

Hong, S., Gronert, K., Devchand, P. R., Moussignac, R. L., and Serhan, C. N. (2003). Novel docosatrienes and 17S-resolvins generated from docosahexaenoic acid in murine brain, human blood, and glial cells. Autacoids in anti-inflammation. J. Biol. Chem. 278, 14677-14687. doi: 10.1074/jbc. m300218200

Hu, B. H., Zheng, X. Y., Mcfadden, S. L., Kopke, R. D., and Henderson, D. (1997). R-phenylisopropyladenosine attenuates noise-induced hearing loss in the chinchilla. Hear. Res. 113, 198-206. doi: 10.1016/s0378-5955(97) 00143-3
Huang, Q., and Tang, J. (2010). Age-related hearing loss or presbycusis. Eur. Arch. Otorhinolaryngol. 267, 1179-1191. doi: 10.1007/s00405-010-1270-7

Hunt, K. J., Walsh, B. M., Voegeli, D., and Roberts, H. C. (2010). Inflammation in aging part 1: physiology and immunological mechanisms. Biol. Res. Nurs. 11, 245-252. doi: 10.1177/1099800409352237

Hutchinson, K. M., Alessio, H., and Baiduc, R. R. (2010). Association between cardiovascular health and hearing function: pure-tone and distortion product otoacoustic emission measures. Am. J. Audiol. 19, 26-35. doi: 10.1044/10590889(2009/09-0009)

Iqbal, A. J., Sampaio, A. L., Maione, F., Greco, K. V., Niki, T., Hirashima, M., et al. (2011). Endogenous galectin-1 and acute inflammation: emerging notion of a galectin-9 pro-resolving effect. Am. J. Pathol. 178, 1201-1209. doi: 10.1016/j. ajpath.2010.11.073

Iwai, H., Baba, S., Omae, M., Lee, S., Yamashita, T., and Ikehara, S. (2008) Maintenance of systemic immune functions prevents accelerated presbycusis. Brain Res. 1208, 8-16. doi: 10.1016/j.brainres.2008.02.069

Iwai, H., Lee, S., Inaba, M., Sugiura, K., Baba, S., Tomoda, K., et al. (2003). Correlation between accelerated presbycusis and decreased immune functions. Exp. Gerontol. 38, 319-325. doi: 10.1016/s0531-5565(02)00177-8

Jenkins, C., Wilson, R., Roberts, J., Miller, H., McKillop, J. H., and Walker, J. J. (2004). Antioxidants: their role in pregnancy and miscarriage. Antioxid. Redox Signal. 2, 623-628. doi: 10.1089/15230860050192369

Jiang, H., Sha, S. H., and Schacht, J. (2005). NF-кB pathway protects cochlear hair cells from aminoglycoside-induced ototoxicity. J. Neurosci. Res. 79, 644-651. doi: 10.1002/jnr.20392

Jin, Y., Arita, M., Zhang, Q., Saban, D. R., Chauhan, S. K., Chiang, N., et al. (2009). Novel anti-inflammatory and proresolving lipid mediators block inflammatory angiogenesis. Invest. Ophthalmol. Vis. Sci. 50, 4743-4752. doi: 10.1167/iovs.082462

Kalinec, F., Webster, P., Maricle, A., Guerrero, D., Chakravarti, D. N., Chakravarti, B., et al. (2009). Glucocorticoid-stimulated, transcriptionindependent release of annexin A1 by cochlear Hensen cells. Br. J. Pharmacol. 158, 1820-1834. doi: 10.1111/j.1476-5381.2009.00473.x

Kamiński, M. M., Röth, D., Krammer, P. H., and Gülow, K. (2013). Mitochondria as oxidative signaling organelles in T-cell activation: physiological role and pathological implications. Arch. Immunol. Ther. Exp. 61, 367-384. doi: 10.1007/s00005-013-0235-0

Kanzaki, J., and Ouchi, T. (1981). Steroid-responsive bilateral sensorineural hearing loss and immune complexes. Arch Otorhinolaryngol. 230, 5-9. doi: $10.1007 /$ bf00665374

Karp, C. L., Flick, L. M., Park, K. W., Softic, S., Greer, T. M., Keledjian, R., et al. (2004). Defective lipoxin-mediated anti-inflammatory activity in the cystic fibrosis airway. Nat. Immunol. 5, 388-392. doi: 10.1038/ni1056

Karpa, M. J., Gopinath, B., Beath, K., Rochtchina, E., Cumming, R. G., Wang, J. J., et al. (2010). Associations between hearing impairment and mortality risk in older persons: the Blue Mountains Hearing Study. Ann. Epidemiol. 20, 452-459. doi: 10.1016/j.annepidem.2010.03.011

Katoh, S., Ishii, N., Nobumoto, A., Takeshita, K., Dai, S. Y., Shinonaga, R., et al. (2007). Galectin-9 inhibits CD44-hyaluronan interaction and suppresses a murine model of allergic asthma. Am. J. Respir. Crit. Care Med. 176, 27-35. doi: 10.1097/01.wox.0000301299.30646.e6

Kaur, T., Borse, V., Sheth, S., Sheehan, K., Ghosh, S., Tupal, S., et al. (2016). Adenosine A1 receptor protects against cisplatin ototoxicity by suppressing the NOX3/STAT1 inflammatory pathway in the cochlea. J. Neurosci. 36, 3962-3977. doi: 10.1523/JNEUROSCI.3111-15.2016

Kaur, T., Mukherjea, D., Sheehan, K., Jajoo, S., Rybak, L. P., and Ramkumar, V. (2011). Short interfering RNA against STAT1 attenuates cisplatin-induced ototoxicity in the rat by suppressing inflammation. Cell Death Dis. 2:e180. doi: 10.1038/cddis.2011.63

Kim, Y. M., Bombeck, C. A., and Billiar, T. R. (1999). Nitric oxide as a bifunctional regulator of apoptosis. Circ. Res. 84, 253-256. doi: 10.1161/01.res.84. 3.253

Kirkegaard, M., Murai, N., Risling, M., Suneson, A., Järlebark, L., and Ulfendahl, M. (2006). Differential gene expression in the rat cochlea after exposure to impulse noise. Neuroscience 142, 425-435. doi: 10.1016/j. neuroscience.2006.06.037

Kitagawa, H., Takenouchi, T., Azuma, R., Wesnes, K. A., Kramer, W. G., Clody, D. E., et al. (2003). Safety, pharmacokinetics and effects on 
cognitive function of multiple doses of GTS-21 in healthy, male volunteers. Neuropsychopharmacology 28, 542-551. doi: 10.1038/sj.npp.1300028

Kohli, P., and Levy, B. D. (2009). Resolvins and protectins: mediating solutions to inflammation. Br. J. Pharmacol. 158, 960-971. doi: 10.1111/j.1476-5381.2009. 00290.x

Kono, H., and Rock, K. L. (2008). How dying cells alert the immune system to danger. Nat. Rev. Immunol. 8, 279-289. doi: 10.1038/nri2215

Koo, J. W., Quintanilla-Dieck, L., Jiang, M., Liu, J., Urdang, Z. D., Allensworth, J. J., et al. (2015). Endotoxemia-mediated inflammation potentiates aminoglycoside-induced ototoxicity. Sci. Transl. Med. 7:298ra118. doi: 10.1126/scitranslmed.aac5546

Köröskényi, K., Duró, E., Pallai, A., Sarang, Z., Kloor, D., Ucker, D., et al. (2011). Involvement of adenosine $A_{2 A}$ receptors in engulfment-dependent apoptotic cell suppression of inflammation. J. Immunol. 186, 7144-7155. doi: $10.4049 /$ jimmunol.1002284

Krishnamoorthy, N., Burkett, P. R., Dalli, J., Abdulnour, R. E., Colas, R., Ramon, S., et al. (2015). Cutting edge: maresin-1 engages regulatory T cells to limit type 2 innate lymphoid cell activation and promote resolution of lung inflammation. J. Immunol. 194, 863-867. doi: 10.4049/jimmunol.1402534

Krishnamoorthy, S., Recchiuti, A., Chiang, N., Fredman, G., and Serhan, C. N. (2012). Resolvin D1 receptor stereoselectivity and regulation of inflammation and proresolving microRNAs. Am. J. Pathol. 180, 2018-2027. doi: 10.1016/j. ajpath.2012.01.028

Krishnamoorthy, S., Recchiuti, A., Chiang, N., Yacoubian, S., Lee, C. H., Yang, R., et al. (2010). Resolvin D1 binds human phagocytes with evidence for proresolving receptors. Proc. Natl. Acad. Sci. U S A 107, 1660-1665. doi: $10.1073 /$ pnas.0907342107

Kujawa, S. G., and Liberman, M. C. (2009). Adding insult to injury: cochlear nerve degeneration after "temporary" noise-induced hearing loss. J. Neurosci. 29, 14077-14085. doi: 10.1523/JNEUROSCI.2845-09.2009

Kusunoki, M., Möeslein, G., Shoji, Y., Fujita, S., Yanagi, H., Sakanoue, Y., et al. (1992). Steroid complications in patients with ulcerative colitis. Dis. Colon Rectum 35, 1003-1009. doi: 10.1007/BF02253508

La, M., Cao, T. V., Cerchiaro, G., Chilton, K., Hirabayashi, J., Kasai, K., et al. (2003). A novel biological activity for galectin-1: inhibition of leukocyteendothelial cell interactions in experimental inflammation. Am. J. Pathol. 163, 1505-1515. doi: 10.1016/S0002-9440(10)63507-9

Lagoutte, E., Mimoun, S., Andriamihaja, M., Chaumontet, C., Blachier, F., and Bouillaud, F. (2010). Oxidation of hydrogen sulfide remains a priority in mammalian cells and causes reverse electron transfer in colonocytes. Biochim. Biophys. Acta 1797, 1500-1511. doi: 10.1016/j.bbabio.2010.04.004

Lasisi, A. O., Fehintola, F. A., Yusuf, O. B., and Olayemi, O. O. (2011). Correlation between serum immunoglobulin $G$ and hearing threshold among elderly subjects with age-related hearing loss. ORL J. Otorhinolaryngol. Relat. Spec. 73, 88-92. doi: 10.1159/000323830

Le, Y., Wang, J. M., Liu, X., Kong, Y., Hou, X., Ruan, L., et al. (2007). Biologically active peptides interacting with the $\mathrm{G}$ protein-coupled formylpeptide receptor. Protein Pept. Lett. 14, 846-853. doi: 10.2174/092986607782110211

Lee, H. N., Na, H. K., and Surh, Y. J. (2013). Resolution of inflammation as a novel chemopreventive strategy. Semin. Immunopathol. 35, 151-161. doi: $10.1007 / \mathrm{s} 00281-013-0363-y$

Lee, K. H., and Warchol, M. E. (2008). Promotion of neurite outgrowth and axon guidance in spiral ganglion cells by netrin-1. Arch. Otolaryngol. Head Neck Surg. 134, 146-151. doi: 10.1001/archoto.2007.6

Leghi, G. E., and Muhlhausler, B. S. (2016). The effect of n-3 LCPUFA supplementation on oxidative stress and inflammation in the placenta and maternal plasma during pregnancy. Prostaglandins Leukot. Essent. Fatty Acids 113, 33-39. doi: 10.1016/j.plefa.2016.08.010

Leng, S. X., Tian, X., Matteini, A., Li, H., Hughes, J., Jain, A., et al. (2011). IL-6-independent association of elevated serum neopterin levels with prevalent frailty in community-dwelling older adults. Age Ageing 40, 475-481. doi: 10.1093/ageing/afr047

Levy, B. D., and Serhan, C. N. (2014). Resolution of acute inflammation in the lung. Annu. Rev. Physiol. 76, 467-492. doi: 10.1146/annurev-physiol-021113-1 70408

Li, S., Hang, L., and Ma, Y. (2016). FGF22 protects hearing function from gentamycin ototoxicity by maintaining ribbon synapse number. Hear. Res. 332, 39-45. doi: 10.1016/j.heares.2015.11.011
Li, H., and Steyger, P. S. (2011). Systemic aminoglycosides are trafficked via endolymph into cochlear hair cells. Sci. Rep. 1:159. doi: 10.1038/srep00159

Liberman, M. C., and Kujawa, S. G. (2017). Cochlear synaptopathy in acquired sensorineural hearing loss: manifestations and mechanisms. Hear. Res. 349, 138-147. doi: 10.1016/j.heares.2017.01.003

Lin, F. R., Metter, E. J., O’Brien, R. J., Resnick, S. M., Zonderman, A. B., and Ferrucci, L. (2011). Hearing loss and incident dementia. Arch. Neurol. 68, 214-220. doi: 10.1001/archneurol.2010.362

Liu, H., and Baliga, R. (2005). Endoplasmic reticulum stress-associated caspase 12 mediates cisplatin-induced LLC-PK1 cell apoptosis. J. Am. Soc. Nephrol. 16, 1985-1992. doi: 10.1681/asn.2004090768

Lowthian, J. A., Britt, C. J., Rance, G., Lin, F. R., Woods, R. L., Wolfe, R., et al. (2016). Slowing the progression of age-related hearing loss: rationale and study design of the ASPIRIN in HEARING, retinal vessels imaging and neurocognition in older generations (ASPREE-HEARING) trial. Contemp. Clin. Trials 46, 60-66. doi: 10.1016/j.cct.2015.11.014

Ly, N. P., Komatsuzaki, K., Fraser, I. P., Tseng, A. A., Prodhan, P., Moore, K. J., et al. (2005). Netrin-1 inhibits leukocyte migration in vitro and in vivo. Proc. Natl. Acad. Sci. U S A 102, 14729-14734. doi: 10.1073/pnas. 0506233102

Maddox, J. F., Hachicha, M., Takano, T., Petasis, N. A., Fokin, V. V., and Serhan, C. N. (1997). Lipoxin A4 stable analogs are potent mimetics that stimulate human monocytes and THP-1 cells via a G-protein-linked lipoxin A4 receptor. J. Biol. Chem. 272, 6972-6978. doi: 10.1074/jbc.272.11.6972

Maddox, J. F., and Serhan, C. N. (1996). Lipoxin A4 and B4 are potent stimuli for human monocyte migration and adhesion: selective inactivation by dehydrogenation and reduction. J. Exp. Med. 183, 137-146. doi: 10.1084/jem. 183.1.137

Maderna, P., and Godson, C. (2009). Lipoxins: resolutionary road. Br. J. Pharmacol. 158, 947-959. doi: 10.1111/j.1476-5381.2009. 00386. $\mathrm{x}$

Mandic, A., Hansson, J., Linder, S., and Shoshan, M. C. (2003). Cisplatin induces endoplasmic reticulum stress and nucleus-independent apoptotic signaling. J. Biol. Chem. 278, 9100-9106. doi: 10.1074/jbc.M210284200

Marcheselli, V. L., Mukherjee, P. K., Arita, M., Hong, S., Antony, R., Sheets, K., et al. (2010). Neuroprotectin D1/protectin D1 stereoselective and specific binding with human retinal pigment epithelial cells and neutrophils. Prostaglandins Leukot. Essent. Fatty Acids 82, 27-34. doi: 10.1016/j.plefa.2009. 10.010

Marcotti, W., van Netten, S. M., and Kros, C. J. (2005). The aminoglycoside antibiotic dihydrostreptomycin rapidly enters mouse outer hair cells through the mechano-electrical transducer channels. J. Physiol. 567, 505-521. doi: 10.1113/jphysiol.2005.085951

McCabe, B. F. (1989). Autoimmune inner ear disease: therapy. Am. J. Otol. 10, 196-197.

Medzhitov, R. (2008). Origin and physiological roles of inflammation. Nature 454, 428-435. doi: 10.1038/nature07201

Medzhitov, R. (2010). Inflammation 2010: new adventures of an old flame. Cell 140, 771-776. doi: $10.1016 /$ j.cell.2010.03.006

Mendez-Huergo, S. P., Maller, S. M., Farez, M. F., Mariño, K., Correale, J., and Rabinovich, G. A. (2014). Integration of lectin-glycan recognition systems and immune cell networks in CNS inflammation. Cytokine Growth Factor Rev. 25, 247-255. doi: 10.1016/j.cytogfr.2014.02.003

Mimoun, S., Andriamihaja, M., Chaumontet, C., Atanasiu, C., Benamouzig, R., Blouin, J. M., et al. (2012). Detoxification of $\mathrm{H}_{2} \mathrm{~S}$ by differentiated colonic epithelial cells: implication of the sulfide oxidizing unit and of the cell respiratory capacity. Antioxid. Redox Signal. 17, 1-10. doi: 10.1089/ars.2011. 4186

Mirakaj, V., Dalli, J., Granja, T., Rosenberger, P., and Serhan, C. N. (2014). Vagus nerve controls resolution and pro-resolving mediators of inflammation. J. Exp. Med. 211, 1037-1048. doi: 10.1084/jem.20132103

Mirakaj, V., Gatidou, D., Pötzsch, C., Konig, K., and Rosenberger, P. (2011). Netrin-1 signaling dampens inflammatory peritonitis. J. Immunol. 186, 549-555. doi: 10.4049/jimmunol.1002671

Mirakaj, V., Thix, C. A., Laucher, S., Mielke, C., Morote-Garcia, J. C., Schmit, M. A., et al. (2010). Netrin-1 dampens pulmonary inflammation during acute lung injury. Am. J. Respir. Crit. Care Med. 181, 815-824. doi: $10.1164 / \mathrm{rccm} .200905-0717$ oc 
Mittal, M., Siddiqui, M. R., Tran, K., Reddy, S. P., and Malik, A. B. (2014). Reactive oxygen species in inflammation and tissue injury. Antioxid. Redox Signal. 20, 1126-1167. doi: 10.1089/ars.2012.5149

Miyahara, T., Runge, S., Chatterjee, A., Chen, M., Mottola, G., Fitzgerald, J. M., et al. (2013). D-series resolvin attenuates vascular smooth muscle cell activation and neointimal hyperplasia following vascular injury. FASEB J. 27, 2220-2232. doi: 10.1096/fj.12-225615

Miyao, M., Firestein, G. S., and Keithley, E. M. (2008). Acoustic trauma augments the cochlear immune response to antigen. Laryngoscope 118, 1801-1808. doi: 10.1097/MLG.0b013e31817e2c27

Möhrle, D., Ni, K., Varakina, K., Bing, D., Lee, S. C., Zimmermann, U., et al. (2016). Loss of auditory sensitivity from inner hair cell synaptopathy can be centrally compensated in the young but not old brain. Neurobiol. Aging 44, 173-184. doi: 10.1016/j.neurobiolaging.2016.05.001

Moraes, L. A., Piqueras, L., and Bishop-Bailey, D. (2006). Peroxisome proliferatoractivated receptors and inflammation. Pharmacol. Ther. 110, 371-385. doi: 10.1016/j.pharmthera.2005.08.007

Morris, T., Stables, M., Colville-Nash, P., Newson, J., Bellingan, G., de Souza, P. M., et al. (2010). Dichotomy in duration and severity of acute inflammatory responses in humans arising from differentially expressed proresolution pathways. Proc. Natl. Acad. Sci. U S A 107, 8842-8847. doi: 10.1073/pnas. 1000373107

Morris, T., Stables, M., Hobbs, A., de Souza, P., Colville-Nash, P., Warner, T., et al. (2009). Effects of low-dose aspirin on acute inflammatory responses in humans. J. Immunol. 183, 2089-2096. doi: 10.4049/jimmunol.0900477

Motterlini, R., and Foresti, R. (2014). Heme oxygenase-1 as a target for drug discovery. Antioxid. Redox Signal. 20, 1810-1826. doi: 10.1089/ars.2013.5658

Murphy, D., and Daniel, S. J. (2011). Intratympanic dexamethasone to prevent cisplatin ototoxicity: a guinea pig model. Otolaryngol. Head Neck Surg. 145, 452-457. doi: 10.1177/0194599811406673

Muzaffar, S., Shukla, N., Bond, M., Newby, A. C., Angelini, G. D., Sparatore, A., et al. (2008). Exogenous hydrogen sulfide inhibits superoxide formation, NOX-1 expression and Racl activity in human vascular smooth muscle cells. J. Vasc. Res. 45, 521-528. doi: 10.1159/000129686

Nakagawa, T., Kumakawa, K., Usami, S., Hato, N., Tabuchi, K., Takahashi, M., et al. (2014). A randomized controlled clinical trial of topical insulin-like growth factor-1 therapy for sudden deafness refractory to systemic corticosteroid treatment. BMC Med. 12:219. doi: 10.1186/s12916-014-0219-x

Nakagawa, T., Sakamoto, T., Hiraumi, H., Kikkawa, Y. S., Yamamoto, N., Hamaguchi, K., et al. (2010). Topical insulin-like growth factor 1 treatment using gelatin hydrogels for glucocorticoid-resistant sudden sensorineural hearing loss: a prospective clinical trial. BMC Med. 8:76. doi: 10.1186/17417015-8-76

Nakai, Y., Konishi, K., Chang, K. C., Ohashi, K., Morisaki, N., Minowa, Y., et al. (1982). Ototoxicity of the anticancer drug cisplatin. An experimental study. Acta Otolaryngol. 93, 227-232. doi: 10.3109/00016488209130876

Nakamoto, T., Mikuriya, T., Sugahara, K., Hirose, Y., Hashimoto, T., Shimogori, H., et al. (2012). Geranylgeranylacetone suppresses noise-induced expression of proinflammatory cytokines in the cochlea. Auris Nasus Larynx 39, 270-274. doi: 10.1016/j.anl.2011.06.001

National Center for Biotechnology Information (2017). PubChem compound database. Available online at: https://pubchem.ncbi.nlm.nih.gov

Nicotera, P., Brune, B., and Bagetta, G. (1997). Nitric oxide: inducer or suppressor of apoptosis? Trends Pharmacol. Sci. 18, 189-190. doi: 10.1016/s01656147(97)90619-2

Norling, L. V., Perretti, M., and Cooper, D. (2009). Endogenous galectins and the control of the host inflammatory response. J. Endocrinol. 201, 169-184. doi: 10.1677/joe-08-0512

Oh, G. S., Kim, H. J., Choi, J. H., Shen, A., Kim, C. H., Kim, S. J., et al. (2011). Activation of lipopolysaccharide-TLR4 signaling accelerates the ototoxic potential of cisplatin in mice. J. Immunol. 186, 1140-1150. doi: 10.4049/jimmunol.1002183

Ohlemiller, K. K. (2009). Mechanisms and genes in human strial presbycusis from animal models. Brain Res. 1277, 70-83. doi: 10.1016/j.brainres.2009.02.079

Okano, T., Nakagawa, T., Kita, T., Kada, S., Yoshimoto, M., Nakahata, T., et al. (2008). Bone marrow-derived cells expressing Ibal are constitutively present as resident tissue macrophages in the mouse cochlea. J. Neurosci. Res. 86, 1758-1767. doi: 10.1002/jnr.21625
Okusa, M. D. (2002). A $2 \mathrm{~A}$ adenosine receptor: a novel therapeutic target in renal disease. Am. J. Physiol. Renal Physiol. 282, F10-F18.

Paksoy, M., Ayduran, E., Sanli, A., Eken, M., Aydin, S., and Oktay, Z. A. (2011). The protective effects of intratympanic dexamethasone and vitamin E on cisplatin-induced ototoxicity are demonstrated in rats. Med. Oncol. 28, 615-621. doi: 10.1007/s12032-010-9477-4

Pálinkás, Z., Furtmüller, P. G., Nagy, A., Jakopitsch, C., Pirker, K. F., Magierowski, M., et al. (2015). Interactions of hydrogen sulfide with myeloperoxidase. Br. J. Pharmacol. 172, 1516-1532. doi: 10.1111/bph.12769

Papayianni, A., Serhan, C. N., Phillips, M. L., Rennke, H. G., and Brady, H. R. (1995). Transcellular biosynthesis of lipoxin A4 during adhesion of platelets and neutrophils in experimental immune complex glomerulonephritis. Kidney Int. 47, 1295-1302. doi: 10.1038/ki.1995.184

Parham, K. (2011). Can intratympanic dexamethasone protect against cisplatin ototoxicity in mice with age-related hearing loss? Otolaryngol. Head Neck Surg. 145, 635-640. doi: 10.1177/0194599811409304

Parolini, S., Santoro, A., Marcenaro, E., Luini, W., Massardi, L., Facchetti, F., et al. (2007). The role of chemerin in the colocalization of NK and dendritic cell subsets into inflamed tissues. Blood 109, 3625-3632. doi: 10.1182/blood-200608-038844

Pathak, R. K., Marrache, S., Choi, J. H., Berding, T. B., and Dhar, S. (2014). The prodrug platin-A: simultaneous release of cisplatin and aspirin. Angew. Chem. Int. Ed Engl. 53, 1963-1967. doi: 10.1002/anie.201308899

Pavlov, V. A., and Tracey, K. J. (2012). The vagus nerve and the inflammatory reflex-linking immunity and metabolism. Nat. Rev. Endocrinol. 8, 743-754. doi: $10.1038 /$ nrendo.2012.189

Perretti, M. (2015). The resolution of inflammation: new mechanisms in patho-physiology open opportunities for pharmacology. Semin. Immunol. 27, 145-148. doi: 10.1016/j.smim.2015.06.001

Perretti, M., and D'Acquisto, F. (2009). Annexin A1 and glucocorticoids as effectors of the resolution of inflammation. Nat. Rev. Immunol. 9, 62-70. doi: $10.1038 /$ nri2470

Perretti, M., and Dalli, J. (2009). Exploiting the Annexin A1 pathway for the development of novel anti-inflammatory therapeutics. Br. J. Pharmacol. 158, 936-946. doi: 10.1111/j.1476-5381.2009.00483.x

Pettitt, T. R., and Rowley, A. F. (1991). Fatty acid composition and lipoxygenase metabolism in blood cells of the lesser spotted dogfish, Scyliorhinus canicula. Comp. Biochem. Physiol. B 99, 647-652. doi: 10.1016/0305-0491(91) 90349-i

Pettitt, T. R., Rowley, A. F., Barrow, S. E., Mallet, A. I., and Secombes, C. J. (1991). Synthesis of lipoxins and other lipoxygenase products by macrophages from the rainbow trout, Oncorhynchus mykiss. J. Biol. Chem. 266, 8720-8726.

Piu, F., Wang, X., Fernandez, R., Dellamary, L., Harrop, A., Ye, Q., et al. (2011). OTO-104: a sustained-release dexamethasone hydrogel for the treatment of otic disorders. Otol. Neurotol. 32, 171-179. doi: 10.1097/mao.0b013e3182009d29

Poorani, R., Bhatt, A. N., Dwarakanath, B. S., and Das, U. N. (2016). COX-2, aspirin and metabolism of arachidonic, eicosapentaenoic and docosahexaenoic acids and their physiological and clinical significance. Eur. J. Pharmacol. 785, 116-132. doi: 10.1016/j.ejphar.2015.08.049

Pouliot, M., Clish, C. B., Petasis, N. A., Van Dyke, T. E., and Serhan, C. N. (2000). Lipoxin $\mathrm{A}_{4}$ analogues inhibit leukocyte recruitment to Porphyromonas gingivalis: a role for cyclooxygenase- 2 and lipoxins in periodontal disease. Biochemistry 39, 4761-4768. doi: 10.1021/bi992551b

Prayle, A. P., Jain, K., Touw, D. J., Koch, B. C., Knox, A. J., Watson, A., et al. (2016). The pharmacokinetics and toxicity of morning vs. evening tobramycin dosing for pulmonary exacerbations of cystic fibrosis: a randomised comparison. J. Cyst. Fibros. 15, 510-517. doi: 10.1016/j.jcf.2015.07.012

Qiu, F. H., Devchand, P. R., Wada, K., and Serhan, C. N. (2001). Aspirin-triggered lipoxin A4 and lipoxin A4 up-regulate transcriptional corepressor NAB1 in human neutrophils. FASEB J. 15, 2736-2738. doi: 10.1096/fj.01-0576fje

Rabinovich, G. A., Alonso, C. R., Sotomayor, C. E., Durand, S., Bocco, J. L., and Riera, C. M. (2000). Molecular mechanisms implicated in galectin-1-induced apoptosis: activation of the AP-1 transcription factor and downregulation of Bcl-2. Cell Death Differ. 7, 747-753. doi: 10.1038/sj.cdd.4400708

Rabinovich, G. A., Baum, L. G., Tinari, N., Paganelli, R., Natoli, C., Liu, F. T., et al. (2002). Galectins and their ligands: amplifiers, silencers or tuners of the inflammatory response? Trends Immunol. 23, 313-320. doi: 10.1016/s14714906(02)02232-9 
Rabinovich, G. A., and Conejo-García, J. R. (2016). Shaping the immune landscape in cancer by galectin-driven regulatory pathways. J. Mol. Biol. 428, 3266-3281. doi: 10.1016/j.jmb.2016.03.021

Rabinovich, G. A., and Croci, D. O. (2012). Regulatory circuits mediated by lectin-glycan interactions in autoimmunity and cancer. Immunity 36, 322-335. doi: 10.1016/j.immuni.2012.03.004

Rabinovich, G. A., and Toscano, M. A. (2009). Turning 'sweet' on immunity: galectin-glycan interactions in immune tolerance and inflammation. Nat. Rev. Immunol. 9, 338-352. doi: 10.1038/nri2536

Ralevic, V., and Burnstock, G. (1998). Receptors for purines and pyrimidines. Pharmacol. Rev. 50, 413-492.

Ramesh, G., and Reeves, W. B. (2004). Salicylate reduces cisplatin nephrotoxicity by inhibition of tumor necrosis factor- $\alpha$. Kidney Int. 65, 490-498. doi: 10.1111/j.1523-1755.2004.00413.x

Ramon, S., Gao, F., Serhan, C. N., and Phipps, R. P. (2012). Specialized proresolving mediators enhance human B cell differentiation to antibodysecreting cells. J. Immunol. 189, 1036-1042. doi: 10.4049/jimmunol.1103483

Reville, K., Crean, J. K., Vivers, S., Dransfield, I., and Godson, C. (2006). Lipoxin A4 redistributes myosin IIA and Cdc42 in macrophages: implications for phagocytosis of apoptotic leukocytes. J. Immunol. 176, 1878-1888. doi: 10.4049/jimmunol.176.3.1878

Robbins, S. L., and Cotran, R. (1979). Pathologic Basis of Disease. Philadelphia, PA: W.B. Saunders Co.

Rock, K. L., Latz, E., Ontiveros, F., and Kono, H. (2010). The sterile inflammatory response. Annu. Rev. Immunol. 28, 321-342. doi: 10.1146/annurev-immunol030409-101311

Romano, M. (2005). Lipoxin analogs and lipoxin formation in vivo. Prostaglandins Leukot. Essent. Fatty Acids 73, 239-243. doi: 10.1016/j.plefa.2005.05.011

Romano, M. (2006). Lipid mediators: lipoxin and aspirin-triggered 15-epi-lipoxins. Inflamm. Allergy Drug Targets 5, 81-90. doi: 10.2174/ 187152806776383152

Rossi, A. G., Hallett, J. M., Sawatzky, D. A., Teixeira, M. M., and Haslett, C. (2007). Modulation of granulocyte apoptosis can influence the resolution of inflammation. Biochem. Soc. Trans. 35, 288-291. doi: 10.1042/bst0350288

Rowley, A. F., Pettitt, T. R., Secombes, C. J., Sharp, G. J., Barrow, S. E., and Mallet, A. I. (1991). Generation and biological activities of lipoxins in the rainbow trout-an overview. Adv. Prostaglandin Thromboxane Leukot. Res. 21B, 557-560.

Rubinstein, N., Ilarregui, J. M., Toscano, M. A., and Rabinovich, G. A. (2004). The role of galectins in the initiation, amplification and resolution of the inflammatory response. Tissue Antigens 64, 1-12. doi: 10.1111/j.0001-2815. 2004.00278.x

Ryan, A., and Godson, C. (2010). Lipoxins: regulators of resolution. Curr. Opin. Pharmacol. 10, 166-172. doi: 10.1016/j.coph.2010.02.005

Rybak, L. P., Whitworth, C. A., Mukherjea, D., and Ramkumar, V. (2007). Mechanisms of cisplatin-induced ototoxicity and prevention. Hear. Res. 226, 157-167. doi: 10.1016/j.heares.2006.09.015

Saitoh, Y., Hosokawa, M., Shimada, A., Watanabe, Y., Yasuda, N., Murakami, Y., et al. (1995). Age-related cochlear degeneration in senescence-accelerated mouse. Neurobiol. Aging 16, 129-136. doi: 10.1016/0197-4580(94) 00153-7

Sautter, N. B., Shick, E. H., Ransohoff, R. M., Charo, I. F., and Hirose, K. (2006). CC chemokine receptor 2 is protective against noise-induced hair cell death: studies in CX3CR1(+/GFP) mice. J. Assoc. Res. Otolaryngol. 7, 361-372. doi: 10.1007/s10162-006-0051-x

Schieber, M., and Chandel, N. S. (2014). ROS function in redox signaling and oxidative stress. Curr. Biol. 24, R453-R462. doi: 10.1016/j.cub.2014.03.034

Schwab, J. M., Chiang, N., Arita, M., and Serhan, C. N. (2007). Resolvin $\mathrm{E} 1$ and protectin D1 activate inflammation-resolution programmes. Nature 447, 869-874. doi: 10.1038/nature05877

Scifres, C. M., and Nelson, D. M. (2009). Intrauterine growth restriction, human placental development and trophoblast cell death. J. Physiol. 587, 3453-3458. doi: 10.1113/jphysiol.2009.173252

Sergeyenko, Y., Lall, K., Liberman, M. C., and Kujawa, S. G. (2013). Age-related cochlear synaptopathy: an early-onset contributor to auditory functional decline. J. Neurosci. 33, 13686-13694. doi: 10.1523/jneurosci.1783-13.2013

Serhan, C. N. (2005). Lipoxins and aspirin-triggered 15-epi-lipoxins are the first lipid mediators of endogenous anti-inflammation and resolution.
Prostaglandins Leukot. Essent. Fatty Acids 73, 141-162. doi: 10.1016/j.plefa. 2005.05.002

Serhan, C. N. (2007). Resolution phase of inflammation: novel endogenous anti-inflammatory and proresolving lipid mediators and pathways. Annu. Rev. Immunol. 25, 101-137. doi: 10.1146/annurev.immunol.25.022106.141647

Serhan, C. N. (2011). The resolution of inflammation: the devil in the flask and in the details. FASEB J. 25, 1441-1448. doi: 10.1096/fj.11-0502ufm

Serhan, C. N., Arita, M., Hong, S., and Gotlinger, K. (2004a). Resolvins, docosatrienes, and neuroprotectins, novel omega-3-derived mediators and their endogenous aspirin-triggered epimers. Lipids 39, 1125-1132. doi: 10.1007/s11745-004-1339-7

Serhan, C. N., Gotlinger, K., Hong, S., and Arita, M. (2004b). Resolvins, docosatrienes, and neuroprotectins, novel omega-3-derived mediators and their aspirin-triggered endogenous epimers: an overview of their protective roles in catabasis. Prostaglandins Other Lipid Mediat. 73, 155-172. doi: 10.1016/s1098-8823(04)00030-9

Serhan, C. N., and Chiang, N. (2004). Novel endogenous small molecules as the checkpoint controllers in inflammation and resolution: entrée for resoleomics. Rheum. Dis. Clin. North Am. 30, 69-95. doi: 10.1016/s0889-857x(03) 00117-0

Serhan, C. N., and Chiang, N. (2008). Endogenous pro-resolving and anti-inflammatory lipid mediators: a new pharmacologic genus. $\mathrm{Br}$. J. Pharmacol. 153, S200-S215. doi: 10.1038/sj.bjp.0707489

Serhan, C. N., and Chiang, N. (2013). Resolution phase lipid mediators of inflammation: agonists of resolution. Curr. Opin. Pharmacol. 13, 632-640. doi: 10.1016/j.coph.2013.05.012

Serhan, C. N., Chiang, N., and Dalli, J. (2015a). The resolution code of acute inflammation: novel pro-resolving lipid mediators in resolution. Semin. Immunol. 27, 200-215. doi: 10.1016/j.smim.2015.03.004

Serhan, C. N., Dalli, J., Colas, R. A., Winkler, J. W., and Chiang, N. (2015b). Protectins and maresins: new pro-resolving families of mediators in acute inflammation and resolution bioactive metabolome. Biochim. Biophys. Acta 1851, 397-413. doi: 10.1016/j.bbalip.2014.08.006

Serhan, C. N., Chiang, N., Dalli, J., and Levy, B. D. (2014). Lipid mediators in the resolution of inflammation. Cold Spring Harb. Perspect. Biol. 7:a016311. doi: $10.1101 /$ cshperspect.a016311

Serhan, C. N., Chiang, N., and Van Dyke, T. E. (2008). Resolving inflammation: dual anti-inflammatory and pro-resolution lipid mediators. Nat. Rev. Immunol. 8, 349-361. doi: 10.1038/nri2294

Serhan, C. N., Clish, C. B., Brannon, J., Colgan, S. P., Chiang, N., and Gronert, K. (2000a). Novel functional sets of lipid-derived mediators with antiinflammatory actions generated from omega-3 fatty acids via cyclooxygenase 2-nonsteroidal antiinflammatory drugs and transcellular processing. J. Exp. Med. 192, 1197-1204. doi: 10.1084/jem.192.8.1197

Serhan, C. N., Takano, T., Chiang, N., Gronert, K., and Clish, C. B. (2000b). Formation of endogenous "antiinflammatory" lipid mediators by transcellular biosynthesis. Lipoxins and aspirin-triggered lipoxins inhibit neutrophil recruitment and vascular permeability. Am. J. Respir. Crit. Care Med. 161, S95-S101. doi: 10.1164/ajrccm.161.supplement_1.ltta-19

Serhan, C. N., Fiore, S., Brezinski, D. A., and Lynch, S. (1993). Lipoxin A4 metabolism by differentiated HL-60 cells and human monocytes: conversion to novel 15-oxo and dihydro products. Biochemistry 32, 6313-6319. doi: $10.1021 /$ bi00076a002

Serhan, C. N., Gotlinger, K., Hong, S., Lu, Y., Siegelman, J., Baer, T., et al. (2006). Anti-inflammatory actions of neuroprotectin D1/protectin D1 and its natural stereoisomers: assignments of dihydroxy-containing docosatrienes. J. Immunol. 176, 1848-1859. doi: 10.4049/jimmunol. 176.3.1848

Serhan, C. N., Hamberg, M., and Samuelsson, B. (1984). Lipoxins: novel series of biologically active compounds formed from arachidonic acid in human leukocytes. Proc. Natl. Acad. Sci. U S A 81, 5335-5339. doi: 10.1073/pnas.81. 17.5335

Serhan, C. N., Maddox, J. F., Petasis, N. A., Akritopoulou-Zanze, I., Papayianni, A., Brady, H. R., et al. (1995). Design of lipoxin A4 stable analogs that block transmigration and adhesion of human neutrophils. Biochemistry 34 , 14609-14615. doi: 10.1021/bi00044a041

Serhan, C. N., and Petasis, N. A. (2011). Resolvins and protectins in inflammation resolution. Chem. Rev. 111, 5922-5943. doi: 10.1021/cr100396c 
Serhan, C. N., and Savill, J. (2005). Resolution of inflammation: the beginning programs the end. Nat. Immunol. 6, 1191-1197. doi: 10.1038/ni1276

Serhan, C. N., Yang, R., Martinod, K., Kasuga, K., Pillai, P. S., Porter, T. F., et al. (2009). Maresins: novel macrophage mediators with potent antiinflammatory and proresolving actions. J. Exp. Med. 206, 15-23. doi: 10.1084/jem.20081880

Sha, S. H., Qiu, J. H., and Schacht, J. (2006). Aspirin to prevent gentamicin-induced hearing loss. N. Engl. J. Med. 354, 1856-1857. doi: 10.1056/nejmc053428

Shi, X., and Nuttall, A. L. (2007). Expression of adhesion molecular proteins in the cochlear lateral wall of normal and PARP-1 mutant mice. Hear. Res. 224, 1-14. doi: 10.1016/j.heares.2006.10.011

Simiele, F., Recchiuti, A., Mattoscio, D., De Luca, A., Cianci, E., Franchi, S., et al. (2012). Transcriptional regulation of the human FPR2/ALX gene: evidence of a heritable genetic variant that impairs promoter activity. FASEB J. 26, 1323-1333. doi: 10.1096/fj.11-198069

Sowinski, K. M., Magner, S. J., Lucksiri, A., Scott, M. K., Hamburger, R. J., and Mueller, B. A. (2008). Influence of hemodialysis on gentamicin pharmacokinetics, removal during hemodialysis and recommended dosing. Clin. J. Am. Soc. Nephrol. 3, 355-361. doi: 10.2215/cjn.02920707

Spite, M., Claria, J., and Serhan, C. N. (2014). Resolvins, specialized proresolving lipid mediators and their potential roles in metabolic diseases. Cell Metab. 19, 21-36. doi: 10.1016/j.cmet.2013.10.006

Sugimoto, M. A., Sousa, L. P., Pinho, V., Perretti, M., and Teixeira, M. M. (2016a). Resolution of inflammation: what controls its onset? Front. Immunol. 7:160. doi: 10.3389/fimmu.2016.00160

Sugimoto, M. A., Vago, J. P., Teixeira, M. M., and Sousa, L. P. (2016b). Annexin A1 and the resolution of inflammation: modulation of neutrophil recruitment, apoptosis, and clearance. J. Immunol. Res. 2016:8239258. doi: $10.1155 / 2016 / 8239258$

Sun, Y. P., Oh, S. F., Uddin, J., Yang, R., Gotlinger, K., Campbell, E., et al. (2007). Resolvin D1 and its aspirin-triggered 17R epimer. Stereochemical assignments, anti-inflammatory properties and enzymatic inactivation. J. Biol. Chem. 282, 9323-9334. doi: 10.1074/jbc.m609212200

Szakmany, T., Hauser, B., and Radermacher, P. (2012). N-acetylcysteine for sepsis and systemic inflammatory response in adults. Cochrane Database Syst. Rev. 12:CD006616. doi: 10.1002/14651858.CD006616.pub2

Tabas, I., and Glass, C. K. (2013). Anti-inflammatory therapy in chronic disease: challenges and opportunities. Science 339, 166-172. doi: 10.1126/science. 1230720

Tan, B. T., Lee, M. M., and Ruan, R. (2008). Bone-marrow-derived cells that home to acoustic deafened cochlea preserved their hematopoietic identity. J. Comp. Neurol. 509, 167-179. doi: 10.1002/cne.21729

Tan, W. J., Thorne, P. R., and Vlajkovic, S. M. (2016). Characterisation of cochlear inflammation in mice following acute and chronic noise exposure. Histochem. Cell Biol. 146, 219-230. doi: 10.1007/s00418-016-1436-5

Tauber, A. I., and Chernyak, L. (1991). Metchnikoff and the Origins of Immunology: From Metaphor to Theory. New York, NY: Oxford University Press.

Taylor, E. L., Megson, I. L., Haslett, C., and Rossi, A. G. (2003). Nitric oxide: a key regulator of myeloid inflammatory cell apoptosis. Cell Death Differ. 10, 418-430. doi: 10.1038/sj.cdd.4401152

Thiemann, S., and Baum, L. G. (2016). Galectins and immune responses-just how do they do those things they do? Annu. Rev. Immunol. 34, 243-264. doi: 10.1146/annurev-immunol-041015-055402

Tornabene, S. V., Sato, K., Pham, L., Billings, P., and Keithley, E. M. (2006). Immune cell recruitment following acoustic trauma. Hear. Res. 222, 115-124. doi: 10.1016/j.heares.2006.09.004

Trinidad, A., Ramírez-Camacho, R., Garcia-Berrocal, J. R., Verdaguer, J. M., and Daza, R. (2005). Labyrinthitis secondary to experimental otitis media. Am. J. Otolaryngol. 26, 226-229. doi: 10.1016/j.amjoto.2005.01.003

Tsuchiyama, Y., Wada, J., Zhang, H., Morita, Y., Hiragushi, K., Hida, K., et al. (2000). Efficacy of galectins in the amelioration of nephrotoxic serum nephritis in Wistar Kyoto rats. Kidney Int. 58, 1941-1952. doi: 10.1046/j.1523-1755.2000. 00366. $\mathrm{x}$

Uchida, Y., Sugiura, S., Ando, F., Nakashima, T., and Shimokata, H. (2011). Molecular genetic epidemiology of age-related hearing impairment. Auris Nasus Larynx 38, 657-665. doi: 10.1016/j.anl.2011.02.005

Urrutia, R. A., and Kalinec, F. (2015). Biology and pathobiology of lipid droplets and their potential role in the protection of the organ of Corti. Hear. Res. 330, 26-38. doi: 10.1016/j.heares.2015.04.015
Varela-Nieto, I., Hartl, M., Gorospe, I., and León, Y. (2007). Anti-apoptotic actions of insulin-like growth factors: lessons from development and implications in neoplastic cell transformation. Curr. Pharm. Des. 13, 687-703. doi: 10.2174/138161207780249164

Verschuur, C., Agyemang-Prempeh, A., and Newman, T. A. (2014). Inflammation is associated with a worsening of presbycusis: evidence from the MRC national study of hearing. Int. J. Audiol. 53, 469-475. doi: 10.3109/14992027.2014. 891057

Vlajkovic, S. M., Guo, C. X., Telang, R., Wong, A. C., Paramananthasivam, V., Boison, D., et al. (2011). Adenosine kinase inhibition in the cochlea delays the onset of age-related hearing loss. Exp. Gerontol. 46, 905-914. doi: 10.1016/j. exger.2011.08.001

Vlajkovic, S. M., Housley, G. D., and Thorne, P. R. (2009). Adenosine and the auditory system. Curr. Neuropharmacol. 7, 246-256. doi: $10.2174 / 157015909789152155$

Vlajkovic, S. M., Lee, K. H., Wong, A. C., Guo, C. X., Gupta, R., Housley, G. D., et al. (2010). Adenosine amine congener mitigates noise-induced cochlear injury. Purinergic Signal. 6, 273-281. doi: 10.1007/s11302-010-9188-5

Wada, K., Qiu, F. H., Stahl, G. L., and Serhan, C. N. (2001). Inosine monophosphate and aspirin-triggered 15-epi-lipoxin A4 act in concert to regulate neutrophil trafficking: additive actions of two new endogenous anti-inflammatory mediators. J. Hematother. Stem Cell Res. 10, 75-79. doi: $10.1089 / 152581601750098273$

Wakabayashi, K., Fujioka, M., Kanzaki, S., Okano, H. J., Shibata, S., Yamashita, D., et al. (2010). Blockade of interleukin-6 signaling suppressed cochlear inflammatory response and improved hearing impairment in noisedamaged mice cochlea. Neurosci. Res. 66, 345-352. doi: 10.1016/j.neures. 2009.12.008

Wallace, J. L., Ianaro, A., Flannigan, K. L., and Cirino, G. (2015). Gaseous mediators in resolution of inflammation. Semin. Immunol. 27, 227-233. doi: 10.1016/j.smim.2015.05.004

Wang, X., Dellamary, L., Fernandez, R., Harrop, A., Keithley, E. M., Harris, J. P., et al. (2009). Dose-dependent sustained release of dexamethasone in inner ear cochlear fluids using a novel local delivery approach. Audiol. Neurootol. 14, 393-401. doi: 10.1159/000241896

Wang, X., Truong, T., Billings, P. B., Harris, J. P., and Keithley, E. M. (2003). Blockage of immune-mediated inner ear damage by etanercept. Otol. Neurotol. 24, 52-57. doi: 10.1097/00129492-200301000-00012

West, A. P., Shadel, G. S., and Ghosh, S. (2011). Mitochondria in innate immune responses. Nat. Rev. Immunol. 11, 389-402. doi: 10.1038/nri2975

White, P. J., Mitchell, P. L., Schwab, M., Trottier, J., Kang, J. X., Barbier, O., et al. (2015). Transgenic $\omega-3$ PUFA enrichment alters morphology and gene expression profile in adipose tissue of obese mice: potential role for protectins. Metabolism 64, 666-676. doi: 10.1016/j.metabol.2015.01.017

Whiteman, M., Armstrong, J. S., Chu, S. H., Jia-Ling, S., Wong, B. S., Cheung, N. S., et al. (2004). The novel neuromodulator hydrogen sulfide: an endogenous peroxynitrite 'scavenger'? J. Neurochem. 90, 765-768. doi: 10.1111/j.1471-4159. 2004.02617.x

Whiteman, M., Cheung, N. S., Zhu, Y. Z., Chu, S. H., Siau, J. L., Wong, B. S., et al. (2005). Hydrogen sulphide: a novel inhibitor of hypochlorous acid-mediated oxidative damage in the brain? Biochem. Biophys. Res. Commun. 326, 794-798. doi: 10.1016/j.bbrc.2004.11.110

Whiteman, M., Li, L., Rose, P., Tan, C. H., Parkinson, D. B., and Moore, P. K. (2010). The effect of hydrogen sulfide donors on lipopolysaccharide-induced formation of inflammatory mediators in macrophages. Antioxid. Redox Signal. 12, 1147-1154. doi: 10.1089/ars.2009.2899

WHO. (2005). WHO Report 2005. Global Tuberculosis Control: Surveillance, Planning, Financing. Geneva: World Health Organization

Wood, M. B., and Zuo, J. (2017). The contribution of immune infiltrates to ototoxicity and cochlear hair cell loss. Front. Cell. Neurosci. 11:106. doi: $10.3389 /$ fncel.2017.00106

Wu, W., Yan, C., Gan, T., Chen, Z., Lu, X., Duerksen-Hughes, P. J., et al. (2010). Nuclear proteome analysis of cisplatin-treated HeLa cells. Mutat. Res. 691, 1-8. doi: 10.1016/j.mrfmmm.2010.06.002

Yamahara, K., Nakagawa, T., Ito, J., Kinoshita, K., Omori, K., and Yamamoto, N. (2017). Netrin 1 mediates protective effects exerted by insulin-like growth factor 1 on cochlear hair cells. Neuropharmacology 119, 26-39. doi: 10.1016/j. neuropharm.2017.03.032 
Yamamoto, H., Omelchenko, I., Shi, X., and Nuttall, A. L. (2009). The influence of NF-кB signal-transduction pathways on the murine inner ear by acoustic overstimulation. J. Neurosci. Res. 87, 1832-1840. doi: 10.1002/jnr.22018

Yang, W., Vethanayagam, R. R., Dong, Y., Cai, Q., and Hu, B. H. (2015). Activation of the antigen presentation function of mononuclear phagocyte populations associated with the basilar membrane of the cochlea after acoustic overstimulation. Neuroscience 303, 1-15. doi: 10.1016/j.neuroscience. 2015.05.081

Yin, M. J., Yamamoto, Y., and Gaynor, R. B. (1998). The anti-inflammatory agents aspirin and salicylate inhibit the activity of IкB kinase- $\beta$. Nature 396, 77-80. doi: $10.1038 / 23948$

Yorgason, J. G., Fayad, J. N., and Kalinec, F. (2006). Understanding drug ototoxicity: molecular insights for prevention and clinical management. Expert Opin. Drug Saf. 5, 383-399. doi: 10.1517/14740338.5.3.383

Yorgason, J. G., Luxford, W., and Kalinec, F. (2011). In vitro and in vivo models of drug ototoxicity: studying the mechanisms of a clinical problem. Expert Opin. Drug Metab. Toxicol. 7, 1521-1534. doi: 10.1517/17425255.2011. 614231

Yu, F., Megyesi, J., and Price, P. M. (2008). Cytoplasmic initiation of cisplatin cytotoxicity. Am. J. Physiol. Renal Physiol. 295, F44-F52. doi: 10.1152/ajprenal. 00593.2007

Zanardo, R. C., Brancaleone, V., Distrutti, E., Fiorucci, S., Cirino, G., and Wallace, J. L. (2006). Hydrogen sulfide is an endogenous modulator of leukocyte-mediated inflammation. FASEB J. 20, 2118-2120. doi: 10.1096/fj.066270fje

Zhang, W., Dai, M., Fridberger, A., Hassan, A., Degagne, J., Neng, L., et al. (2012). Perivascular-resident macrophage-like melanocytes in the inner ear are essential for the integrity of the intrastrial fluid-blood barrier. Proc. Natl. Acad. Sci. U S A 109, 10388-10393. doi: 10.1073/pnas.12052 10109
Zhang, G., Sun, L., Lu, X., Chen, Z., Duerksen-Hughes, P. J., Hu, H., et al. (2012). Cisplatin treatment leads to changes in nuclear protein and microRNA expression. Mutat. Res. 746, 66-77. doi: 10.1016/j.mrgentox. 2012.03.004

Zhang, K., and Kaufman, R. J. (2008). From endoplasmic-reticulum stress to the inflammatory response. Nature 454, 455-462. doi: 10.1038/nature07203

Zhou, Y., Zheng, G., Zheng, H., Zhou, R., Zhu, X., and Zhang, Q. (2013). Primary observation of early transtympanic steroid injection in patients with delayed treatment of noise-induced hearing loss. Audiol. Neurootol. 18, 89-94. doi: 10.1159/000345208

Zhu, C., Anderson, A. C., Schubart, A., Xiong, H., Imitola, J., Khoury, S. J., et al. (2005). The Tim-3 ligand galectin-9 negatively regulates $\mathrm{T}$ helper type 1 immunity. Nat. Immunol. 6, 1245-1252. doi: 10.1038/ni1271

Zitvogel, L., Kepp, O., and Kroemer, G. (2010). Decoding cell death signals in inflammation and immunity. Cell 140, 798-804. doi: 10.1016/j.cell.2010.02.015

Conflict of Interest Statement: The authors declare that the research was conducted in the absence of any commercial or financial relationships that could be construed as a potential conflict of interest.

The reviewer MJ and handling Editor declared their shared affiliation, and the handling Editor states that the process nevertheless met the standards of a fair and objective review.

Copyright (c) 2017 Kalinec, Lomberk, Urrutia and Kalinec. This is an open-access article distributed under the terms of the Creative Commons Attribution License (CC $B Y)$. The use, distribution or reproduction in other forums is permitted, provided the original author(s) or licensor are credited and that the original publication in this journal is cited, in accordance with accepted academic practice. No use, distribution or reproduction is permitted which does not comply with these terms. 